\title{
How to make a glycopeptide: a synthetic biology approach to expand antibiotic chemical diversity
}

Grace Yim ${ }^{1}$, Wenliang Wang ${ }^{1}$, Maulik N. Thaker ${ }^{1,2}$, Stephanie Tan ${ }^{1}$, Gerard D. Wright ${ }^{1 *}$

${ }^{1}$ M.G. DeGroote Institute for Infectious Disease Research, Department of Biochemistry and Biomedical Sciences, McMaster University, Hamilton, Ontario, L8S 4K1, Canada

${ }^{2}$ Synthetic Biology Team, Global Discovery Chemistry, Novartis Institutes for Biomedical Research, 700 Main St, Cambridge, MA 02139, USA (current address)

*Email: wrightge@mcmaster.ca

\section{Supporting Information Table of Contents}

Figure S1. HPLC/ESI-MS of GPA compounds produced by

S. coelicolor M1146 pA47934 $\Delta$ staL

Figure S2. Structures encoded by the biosynthetic clusters used as sources for GPA tailoring genes.

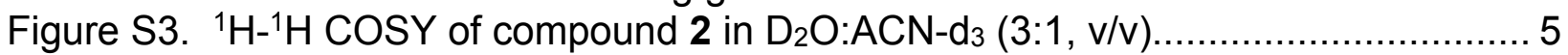

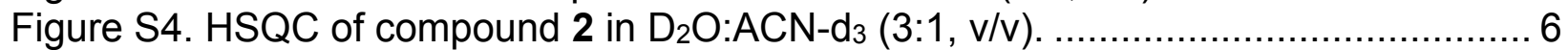

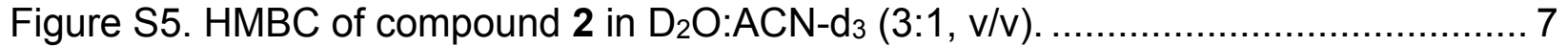

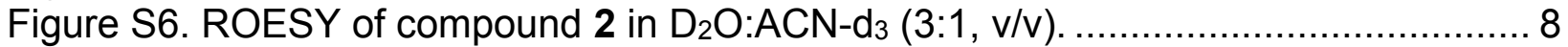

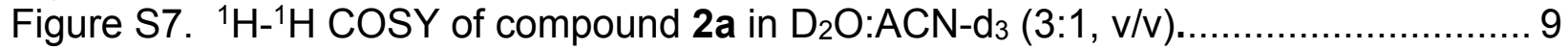

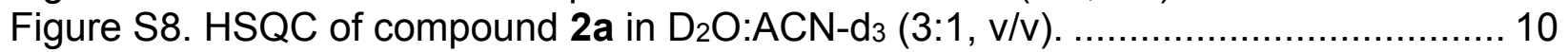

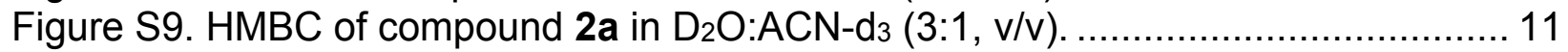

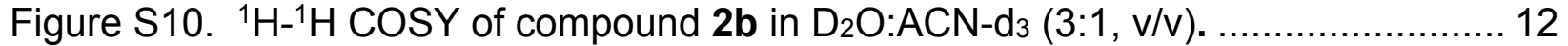

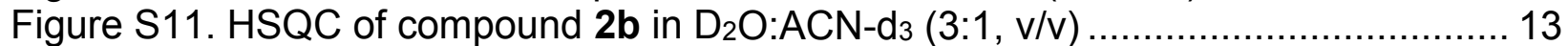

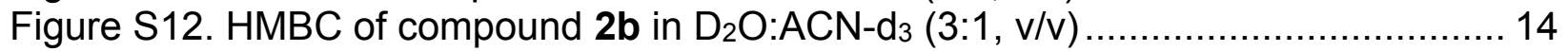

Figure S13. ${ }^{1} \mathrm{H}-{ }^{1} \mathrm{H}$ COSY of compound $2 \mathbf{d}$ in $\mathrm{D}_{2} \mathrm{O}: \mathrm{ACN}-\mathrm{d}_{3}(3: 1, \mathrm{v} / \mathrm{v}) \ldots \ldots \ldots \ldots \ldots \ldots \ldots . . . \ldots \ldots$

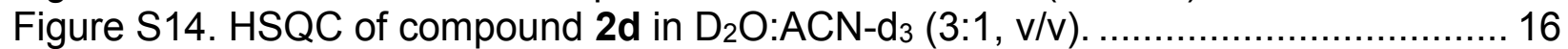

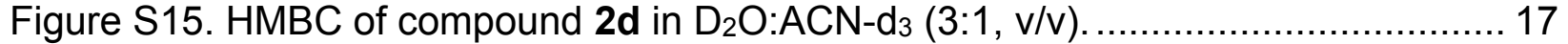

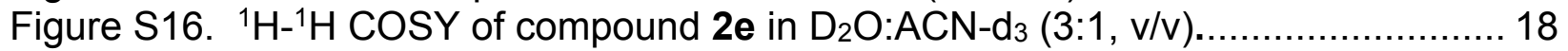

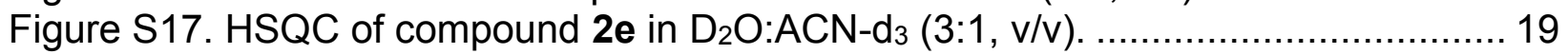

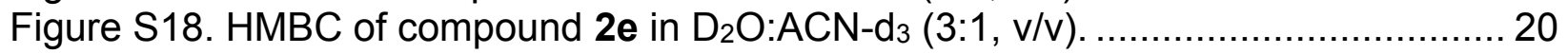

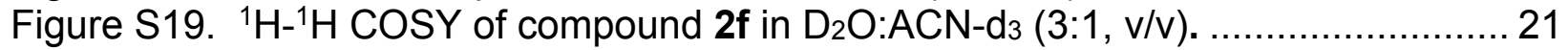

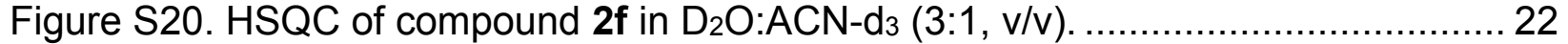

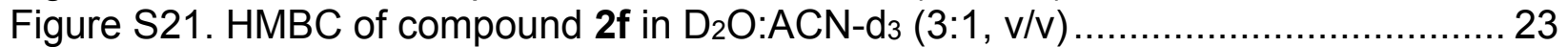

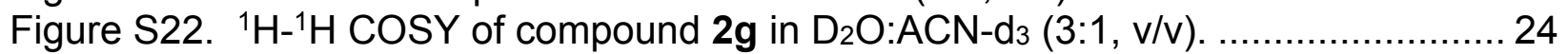

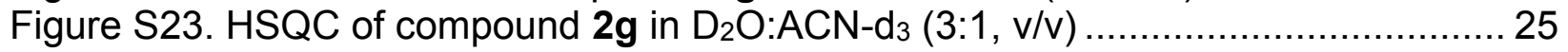

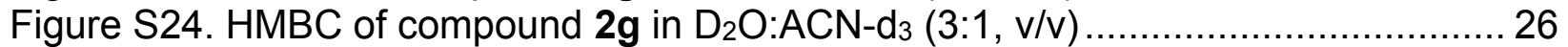

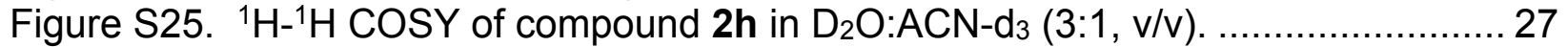

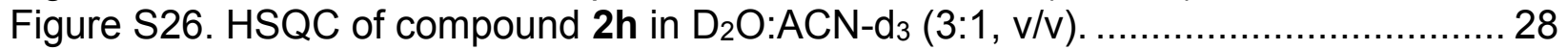

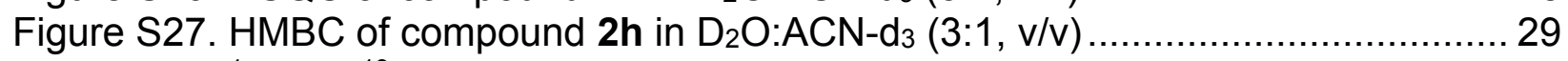

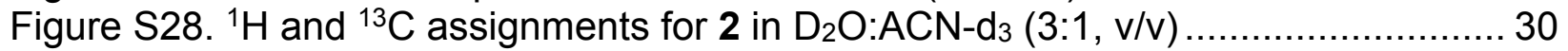

Figure S29. Key correlations and ${ }^{1} \mathrm{H}$ and ${ }^{13} \mathrm{C}$ assignments for $\mathbf{2 a}, \mathbf{2 b}$,

$\mathbf{2 d}, \mathbf{2 e}, \mathbf{2} \mathbf{f}$ and $\mathbf{2 h}$ in $\mathrm{D}_{2} \mathrm{O}: \mathrm{ACN}-\mathrm{d}_{3}(3: 1, \mathrm{v} / \mathrm{v})$ or DMSO-d $6 \ldots \ldots . . .31-32$

Figure S30. MS/MS fragmentation of compounds $\mathbf{2 h - 2 j}$ and $\mathbf{1 a - 1 e} \ldots \ldots \ldots \ldots \ldots \ldots . . . . . . . .33-37$

Figure S31 HPLC/ESI-MS of GPA compounds produced by S. coelicolor

M1146 pA47934 $\Delta$ staL orf22ris .................................................. 38

Figure S32. Colorimetric reporter assays with van promoter................................... 39 
Figure S33. Schematic of restriction sites used to clone tailoring genes into plJ10257 and derivative plasmids.

Table S1. Theoretical and observed high resolution masses for compounds $2-2 \mathrm{j}$ and $\mathbf{1 - 1 e}$.

Table S2. Selected ${ }^{1} \mathrm{H}$ and ${ }^{13} \mathrm{C}$ assignments of novel derivatives $\mathbf{2 a}, \mathbf{2} \mathbf{d}-\mathbf{2} \mathbf{h}$ in $\mathrm{D}_{2} \mathrm{O}: \mathrm{ACN}^{-\mathrm{d}_{3}}(3: 1, \mathrm{v} / \mathrm{v})$ and DMSO-d6.

Table S3. Expected and observed masses from strains with two gene integrations

Table S4. Oligonucleotides used in this study ........................................ 43-44

Supplemental methods $45-46$ 


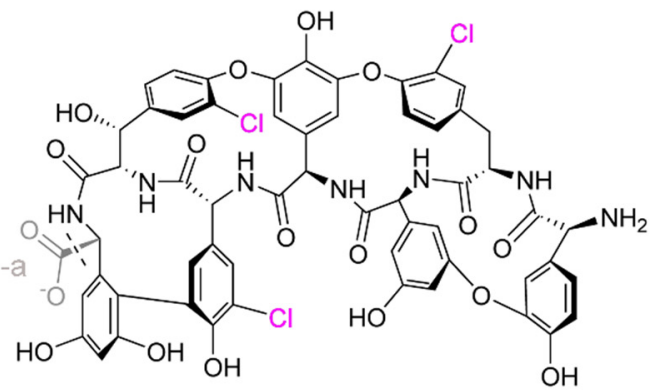

a
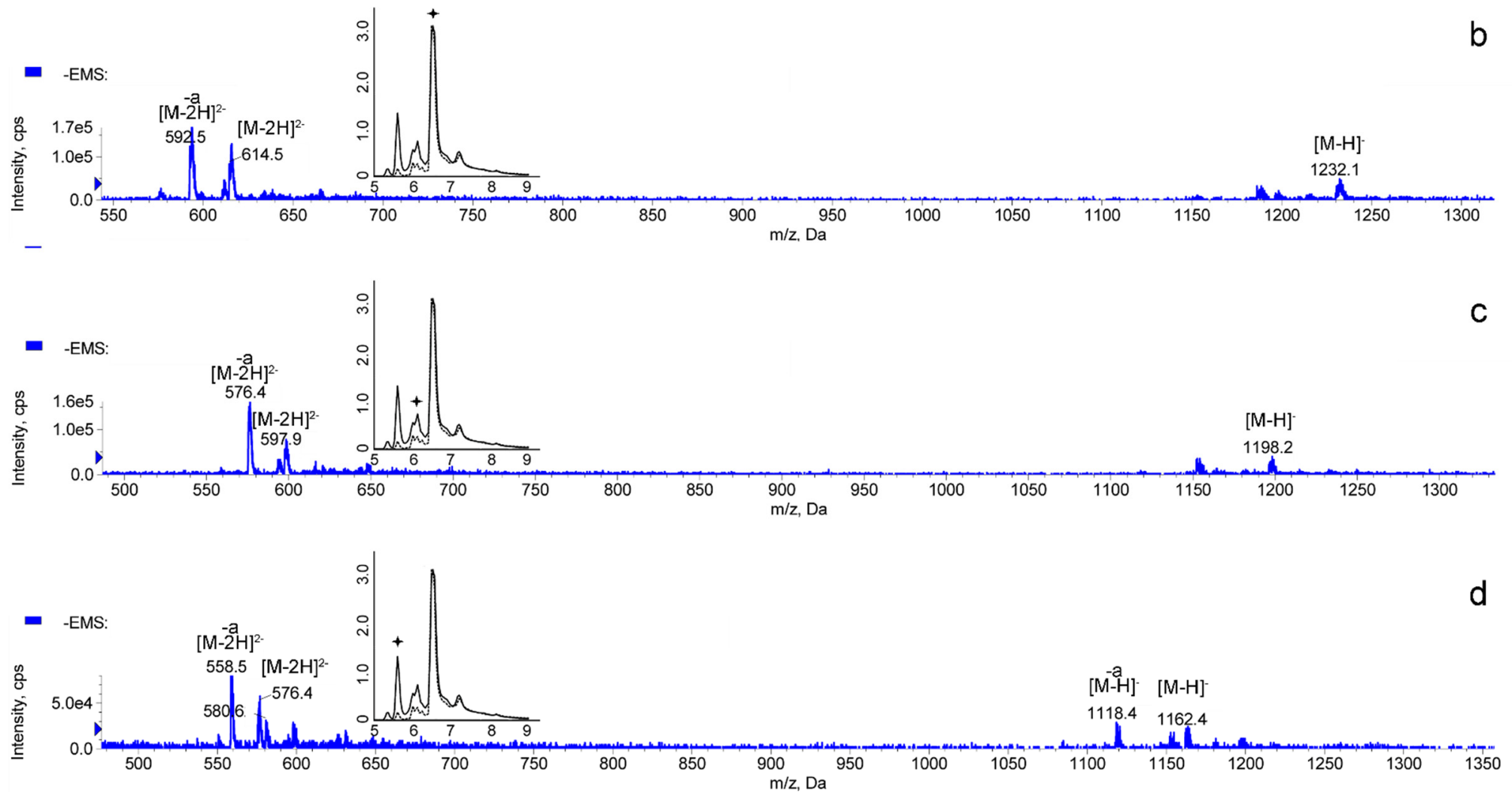

Figure S1. HPLC/ESI-MS of GPA compounds produced by S. coelicolor M1146 pA47934 $\Delta$ staL. After affinity chromatography, the partially purified fermentation of 2 was analyzed. The MS spectra and LC spectra have a lag time of $\sim 0.2 \mathrm{~min}$. The mass spectra of 2 (a), the dichlorinated derivative of $2(b)$ and the mono-chlorinated derivative of 2 (c) and the absorption spectra at 280 nm (d) are shown. 

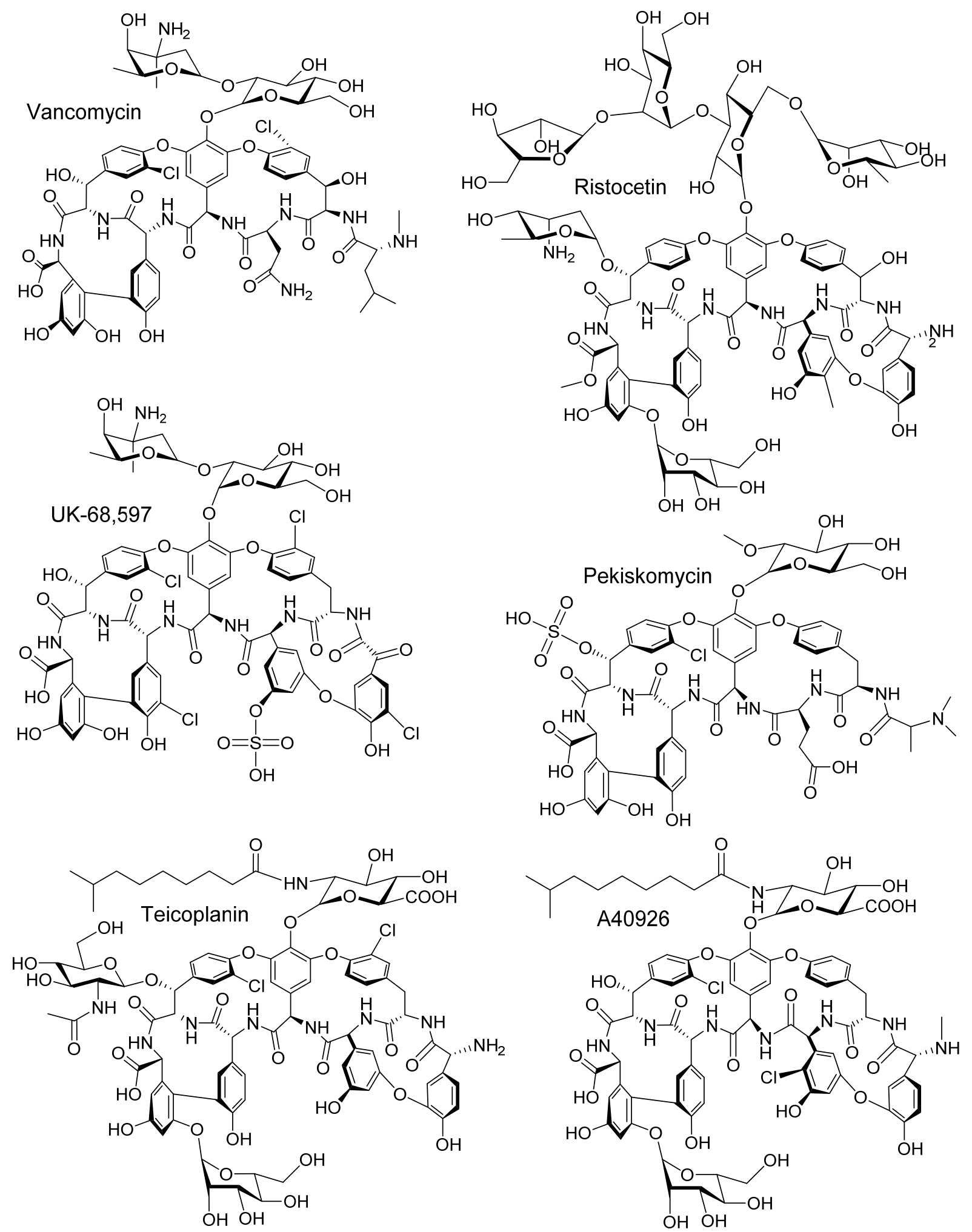

Figure S2. Structures encoded by the biosynthetic clusters used as sources for GPA tailoring genes. The compound encoded by the TEG biosynthetic cluster is not shown as it was a predicted molecule from a metagenomic study in which only the sulfotransferases were characterized (ref 10). 


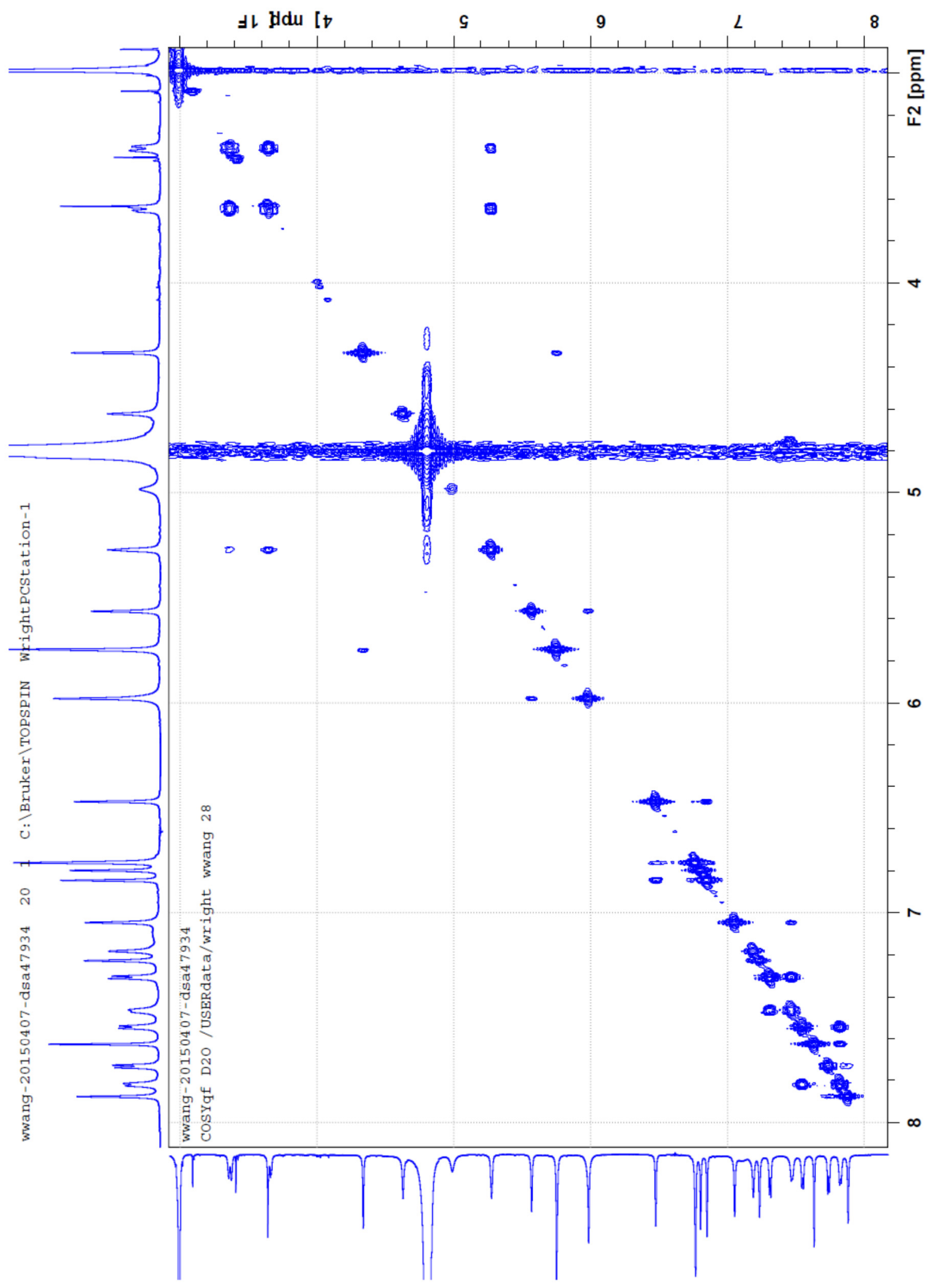

Figure S3. ${ }^{1} \mathrm{H}-{ }^{1} \mathrm{H}$ COSY of compound 2 in $\mathrm{D}_{2} \mathrm{O}: \mathrm{ACN}-\mathrm{d}_{3}(3: 1, \mathrm{v} / \mathrm{v})$. 


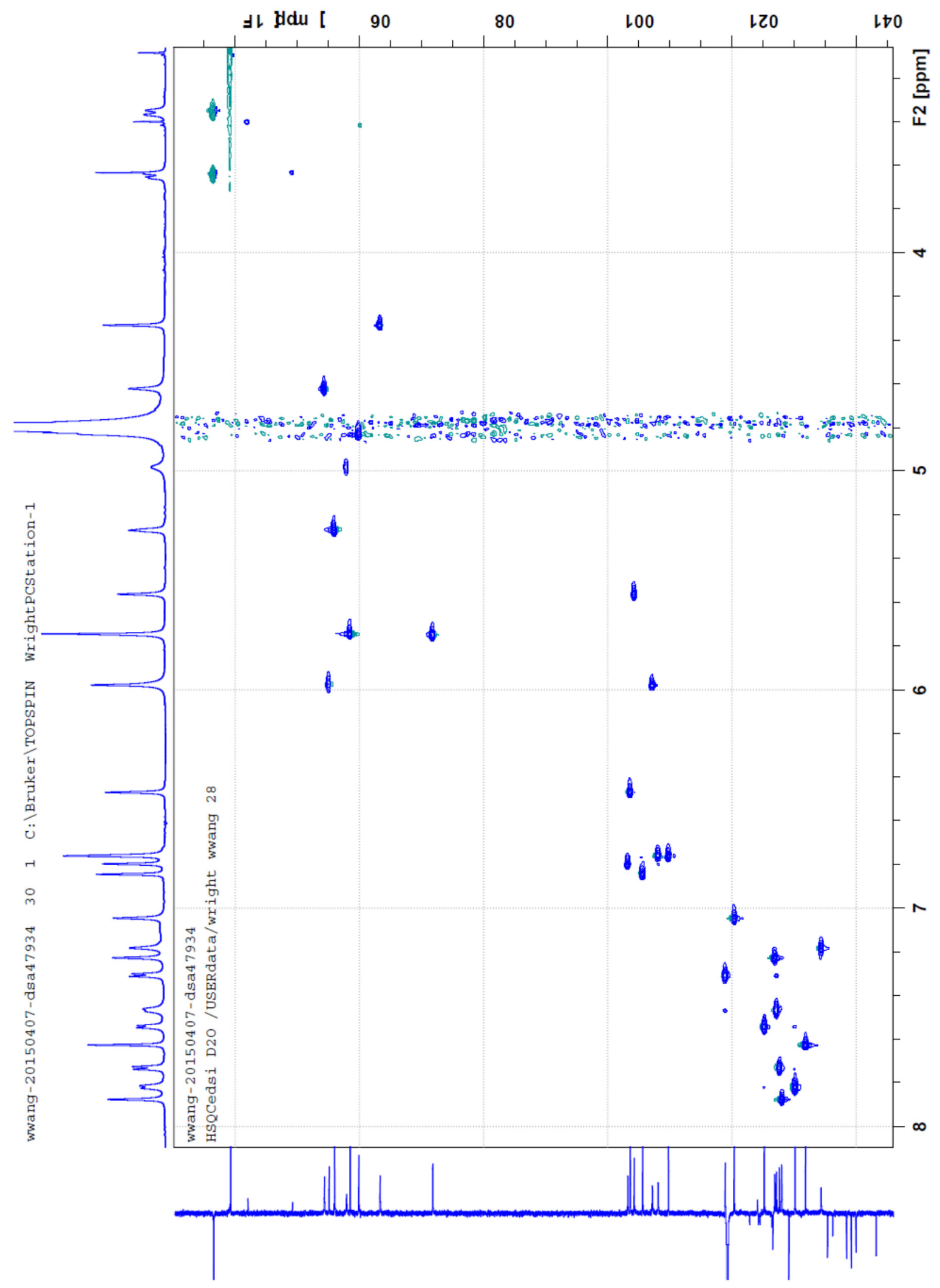

Figure S4. HSQC of compound 2 in $\mathrm{D}_{2} \mathrm{O}: \mathrm{ACN}-\mathrm{d}_{3}(3: 1, \mathrm{v} / \mathrm{v})$. 


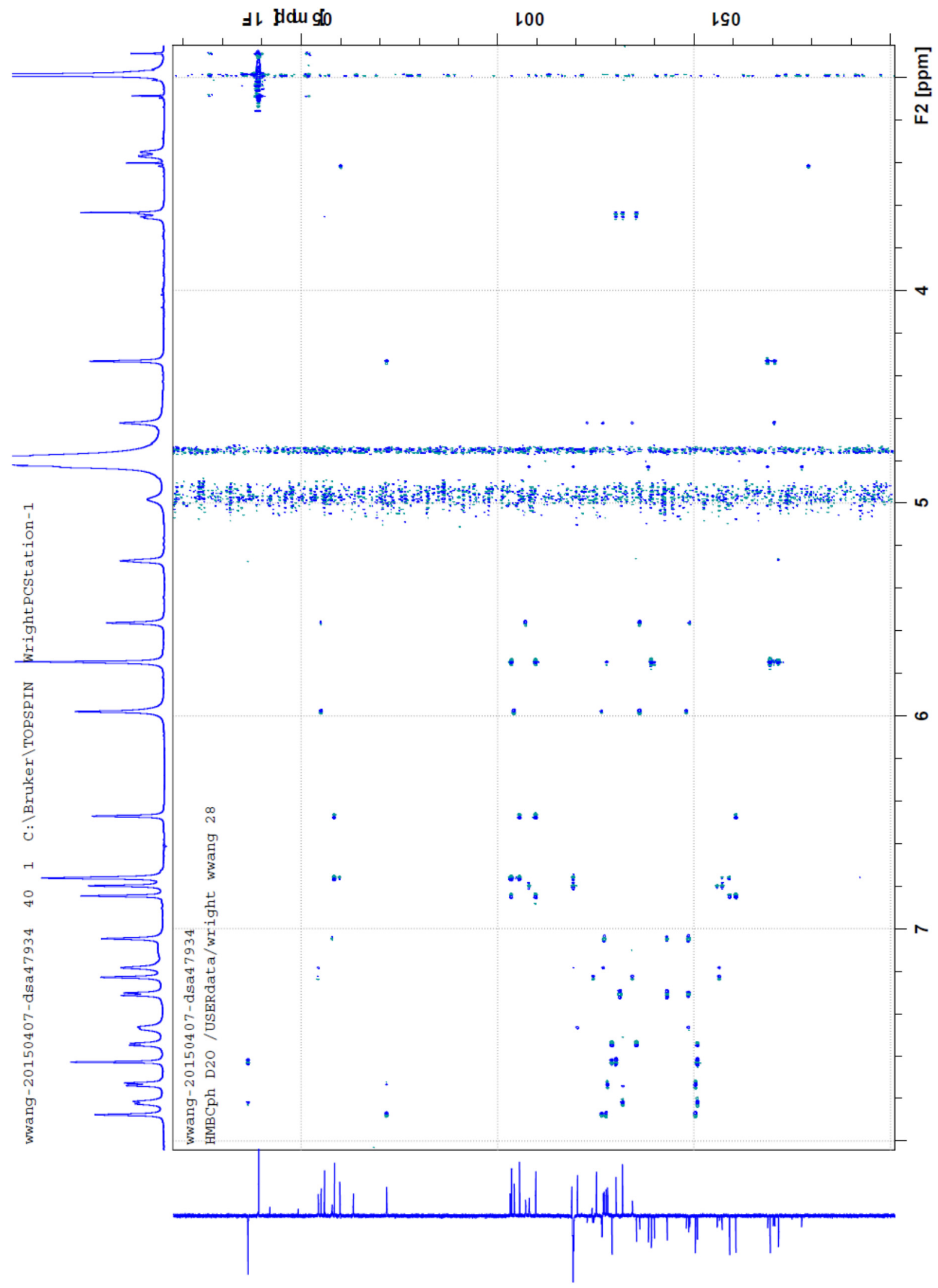

Figure S5. HMBC of compound 2 in $\mathrm{D}_{2} \mathrm{O}: \mathrm{ACN}-\mathrm{d}_{3}(3: 1, \mathrm{v} / \mathrm{v})$. 


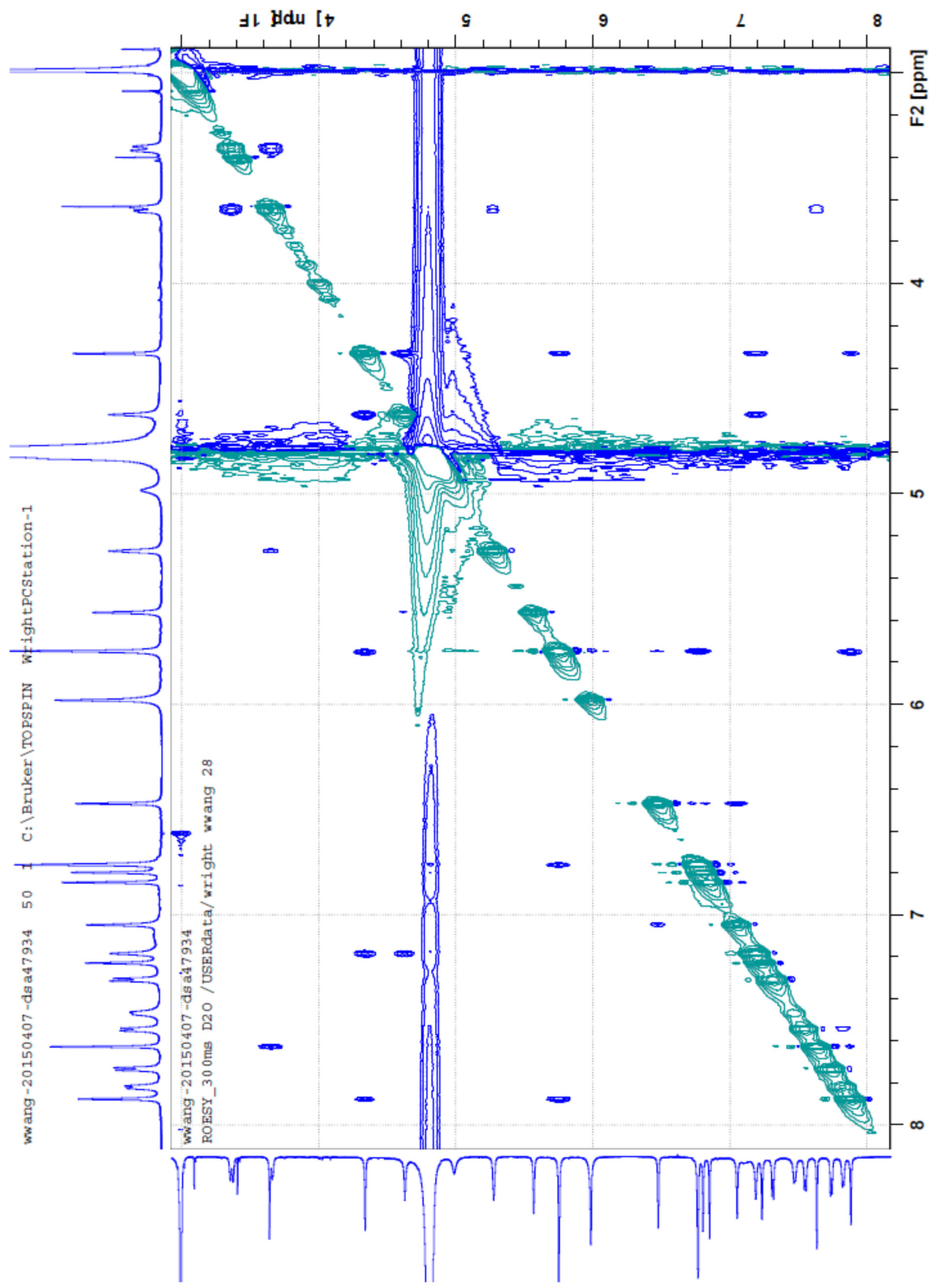

Figure S6. ROESY of compound 2 in $\mathrm{D}_{2} \mathrm{O}: \mathrm{ACN}-\mathrm{d}_{3}(3: 1, \mathrm{v} / \mathrm{v})$. 


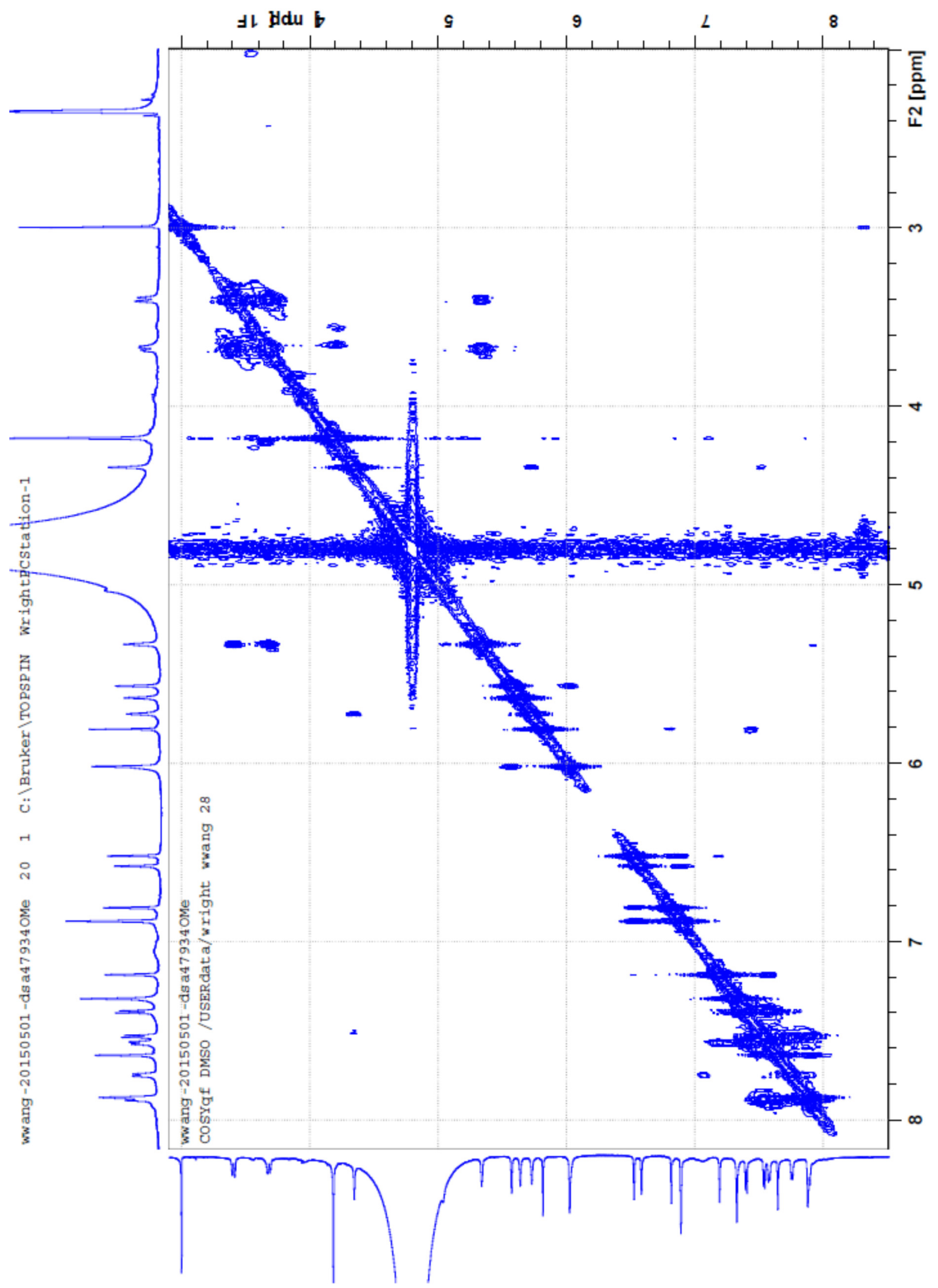

Figure S7. ${ }^{1} \mathrm{H}-{ }^{1} \mathrm{H}$ COSY of compound $2 \mathrm{a}$ in $\mathrm{D}_{2} \mathrm{O}: \mathrm{ACN}-\mathrm{d}_{3}(3: 1, \mathrm{v} / \mathrm{v})$. 


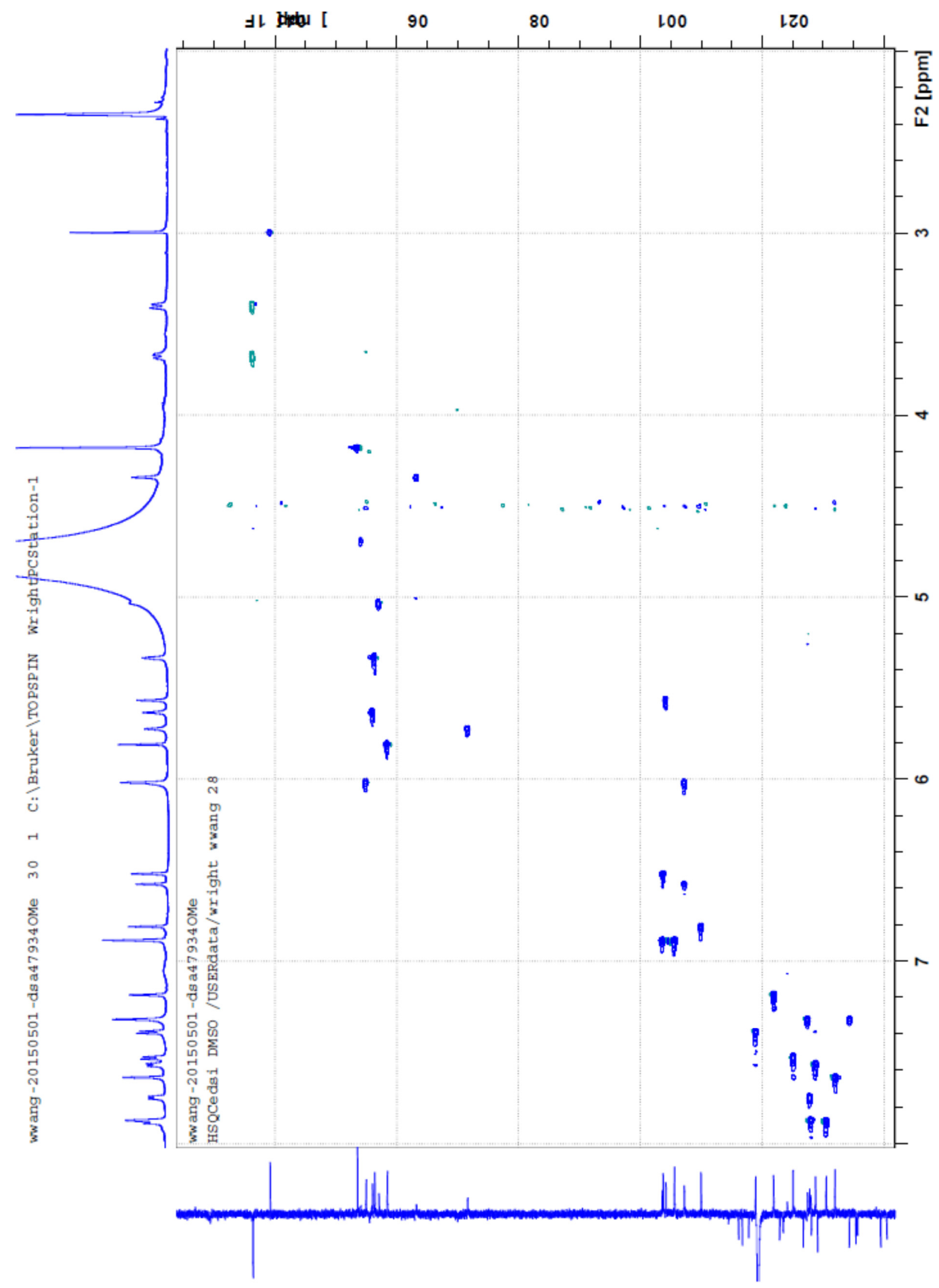

Figure S8. HSQC of compound $2 a$ in $D_{2} \mathrm{O}: A C N-d_{3}(3: 1, v / v)$. 


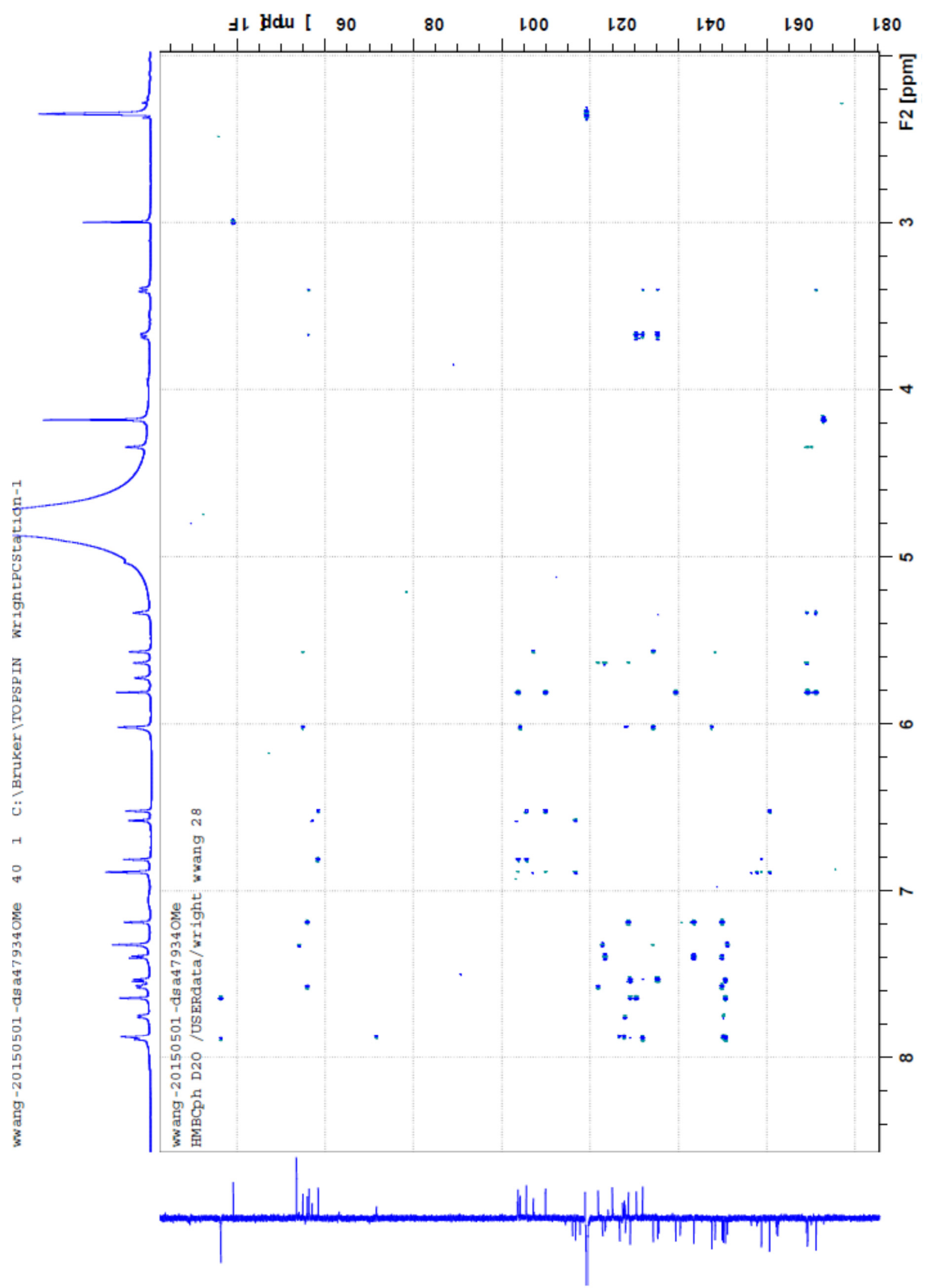

Figure S9. HMBC of compound $2 \mathrm{a}$ in $\mathrm{D}_{2} \mathrm{O}: \mathrm{ACN}-\mathrm{d}_{3}(3: 1, \mathrm{v} / \mathrm{v})$. 


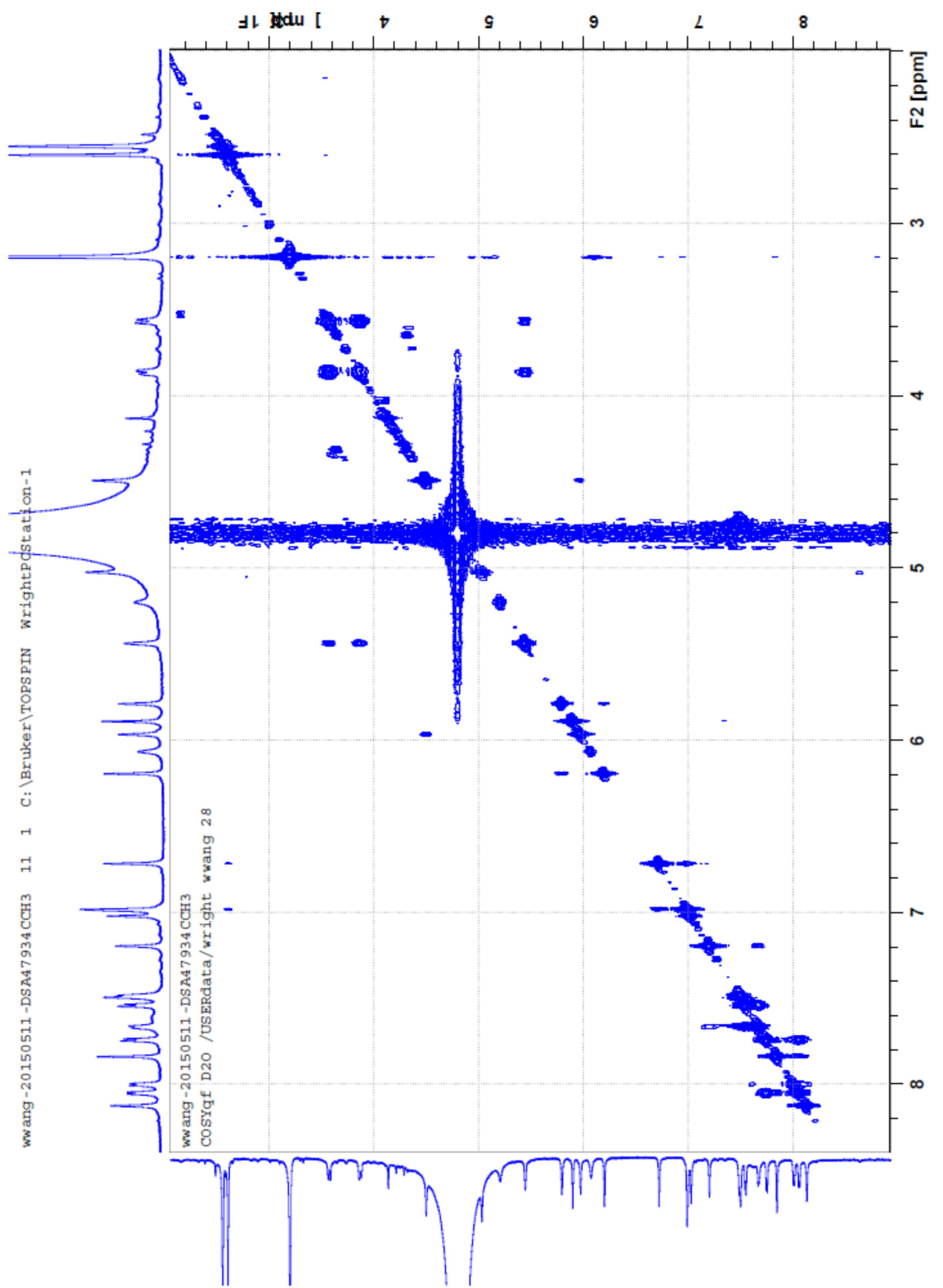

Figure S10. ${ }^{1} \mathrm{H}-{ }^{1} \mathrm{H}$ COSY of compound $\mathbf{2 b}$ in $\mathrm{D}_{2} \mathrm{O}: \mathrm{ACN}-\mathrm{d}_{3}(3: 1, \mathrm{v} / \mathrm{v})$. 


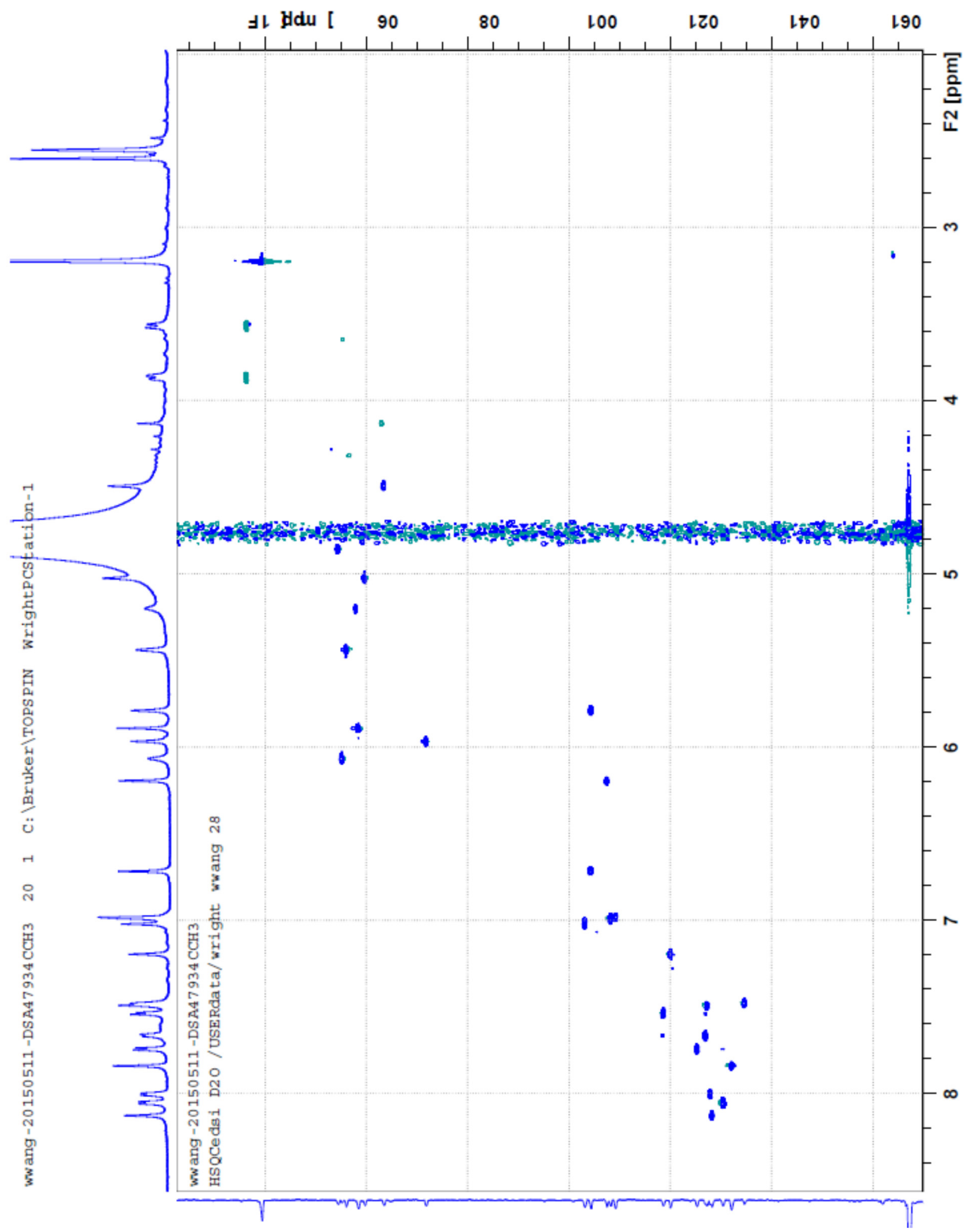

Figure $\mathrm{S} 11$. HSQC of compound $\mathbf{2} \mathbf{b}$ in $\mathrm{D}_{2} \mathrm{O}: \mathrm{ACN}-\mathrm{d}_{3}(3: 1, \mathrm{v} / \mathrm{v})$. 

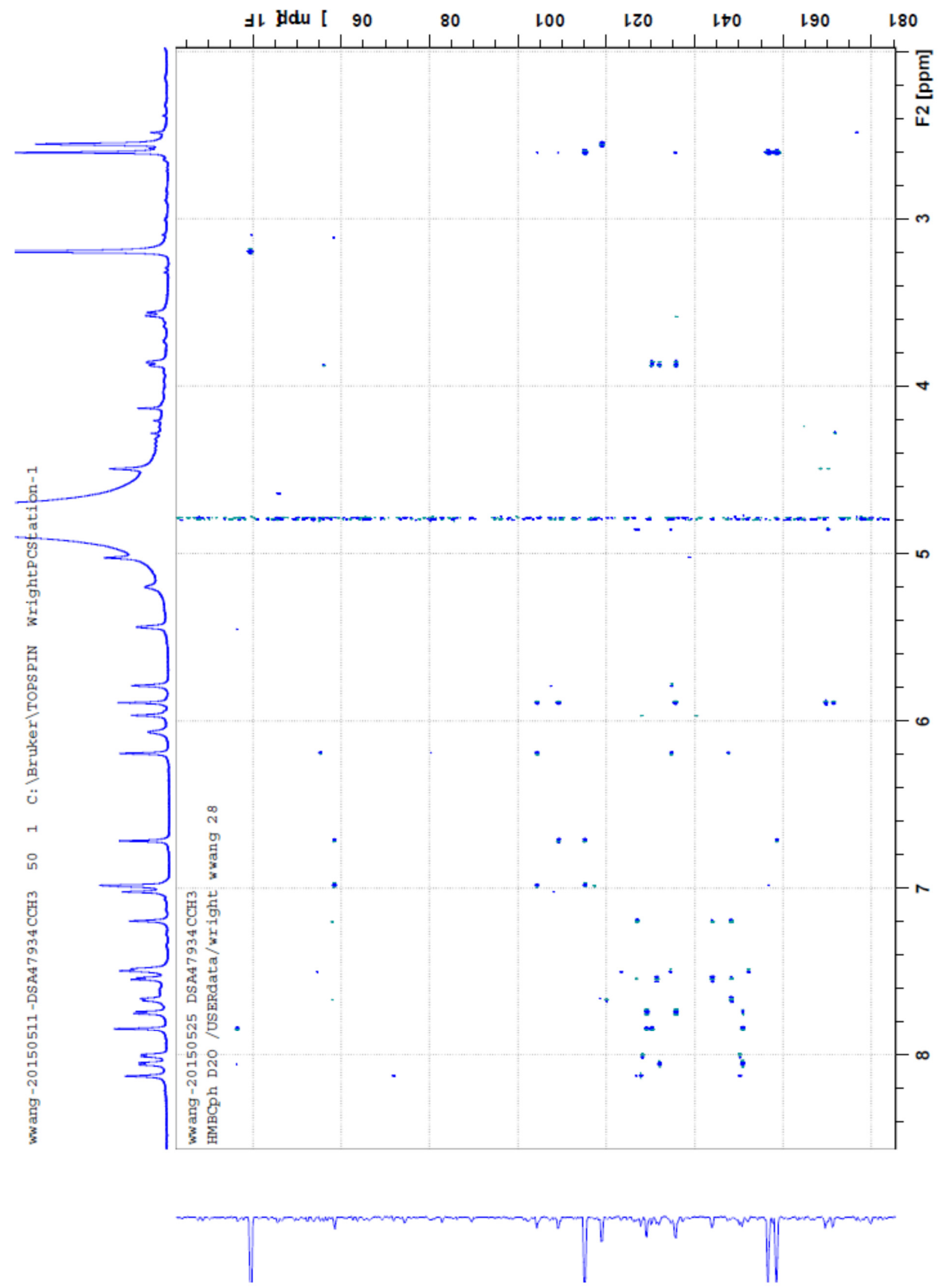

Figure $\mathrm{S} 12 . \mathrm{HMBC}$ of compound $\mathbf{2} \mathbf{b}$ in $\mathrm{D}_{2} \mathrm{O}: \mathrm{ACN}-\mathrm{d}_{3}(3: 1, \mathrm{v} / \mathrm{v})$. 


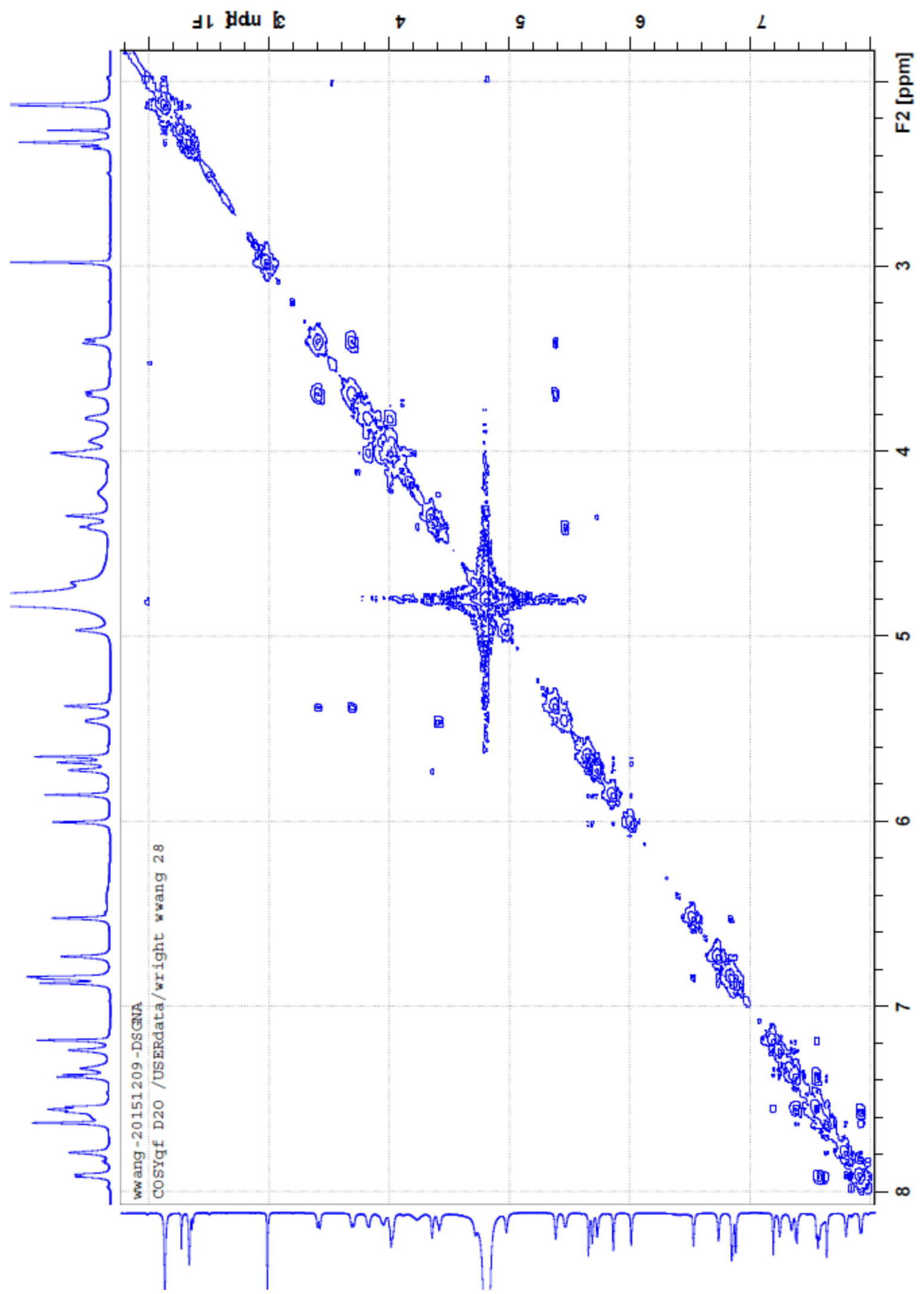

Figure $\mathrm{S} 13 .{ }^{1} \mathrm{H}-{ }^{1} \mathrm{H}$ COSY of compound $\mathbf{2} \mathbf{d}$ in $\mathrm{D}_{2} \mathrm{O}: \mathrm{ACN}-\mathrm{d}_{3}(3: 1, \mathrm{v} / \mathrm{v})$. 


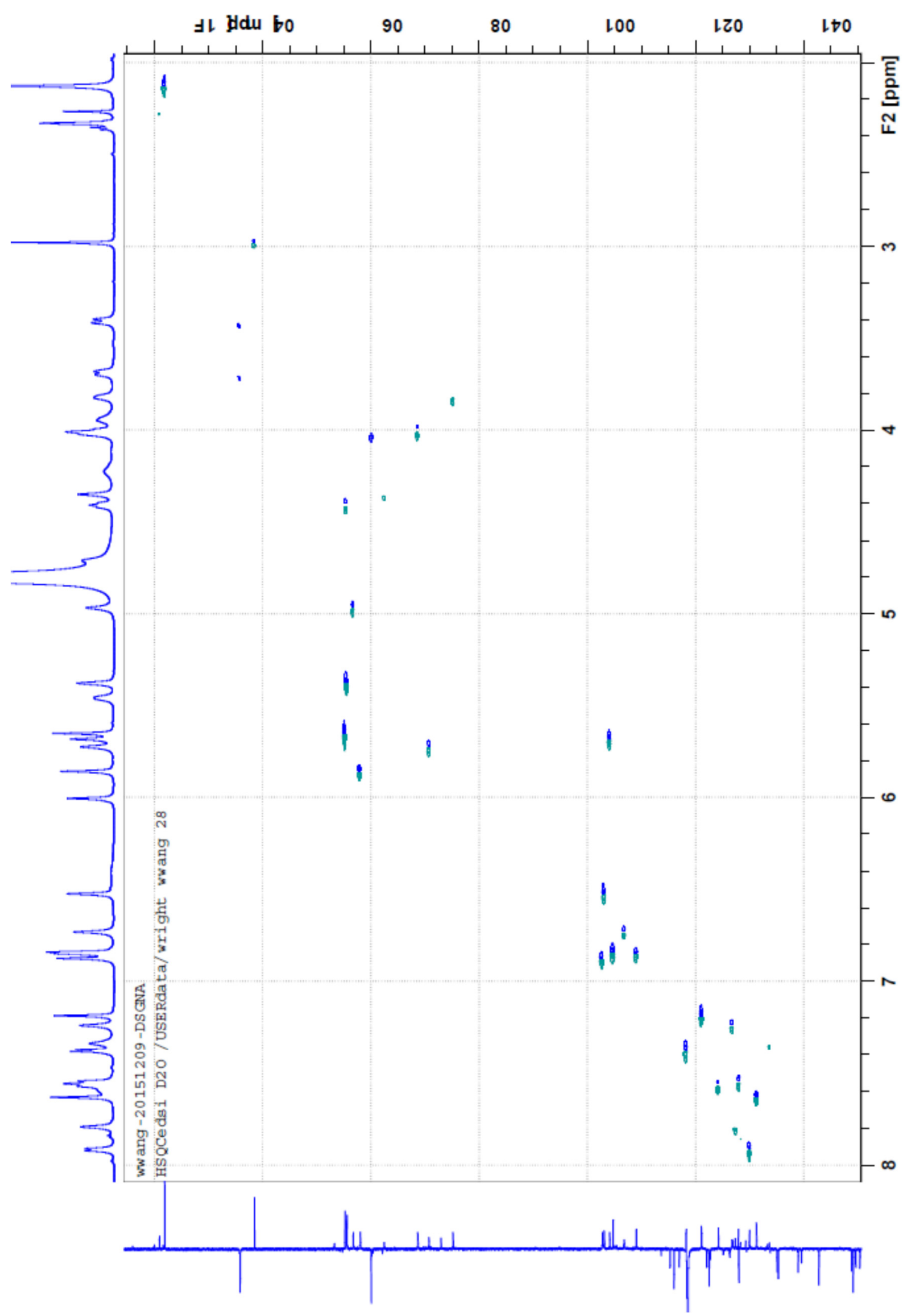

Figure S14. HSQC of compound $\mathbf{2 d}$ in $\mathrm{D}_{2} \mathrm{O}: \mathrm{ACN}-\mathrm{d}_{3}(3: 1, \mathrm{v} / \mathrm{v})$. 


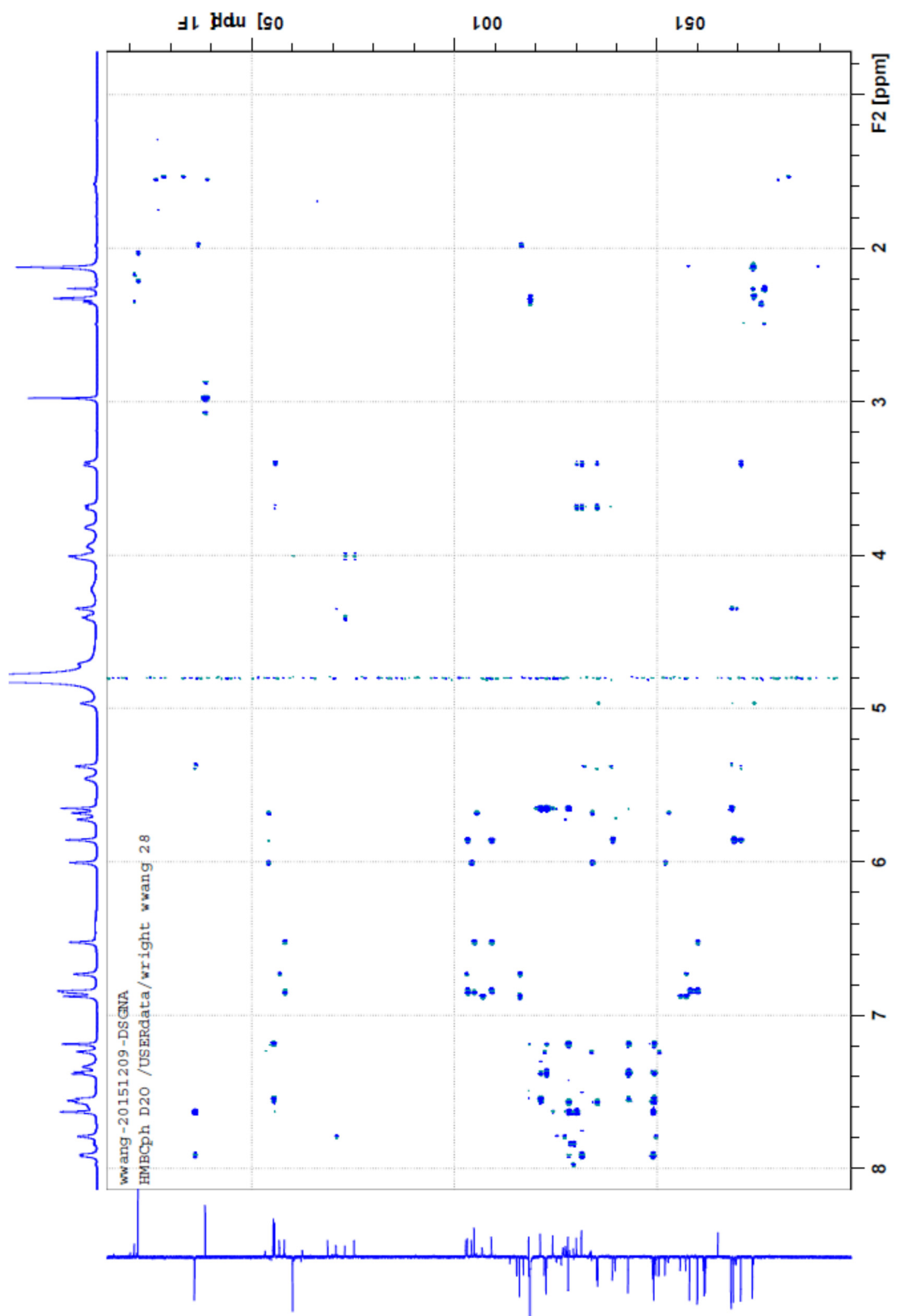

Figure $\mathrm{S} 15 . \mathrm{HMBC}$ of compound $\mathbf{2} \mathbf{d}$ in $\mathrm{D}_{2} \mathrm{O}: \mathrm{ACN}-\mathrm{d}_{3}(3: 1, \mathrm{v} / \mathrm{v})$. 


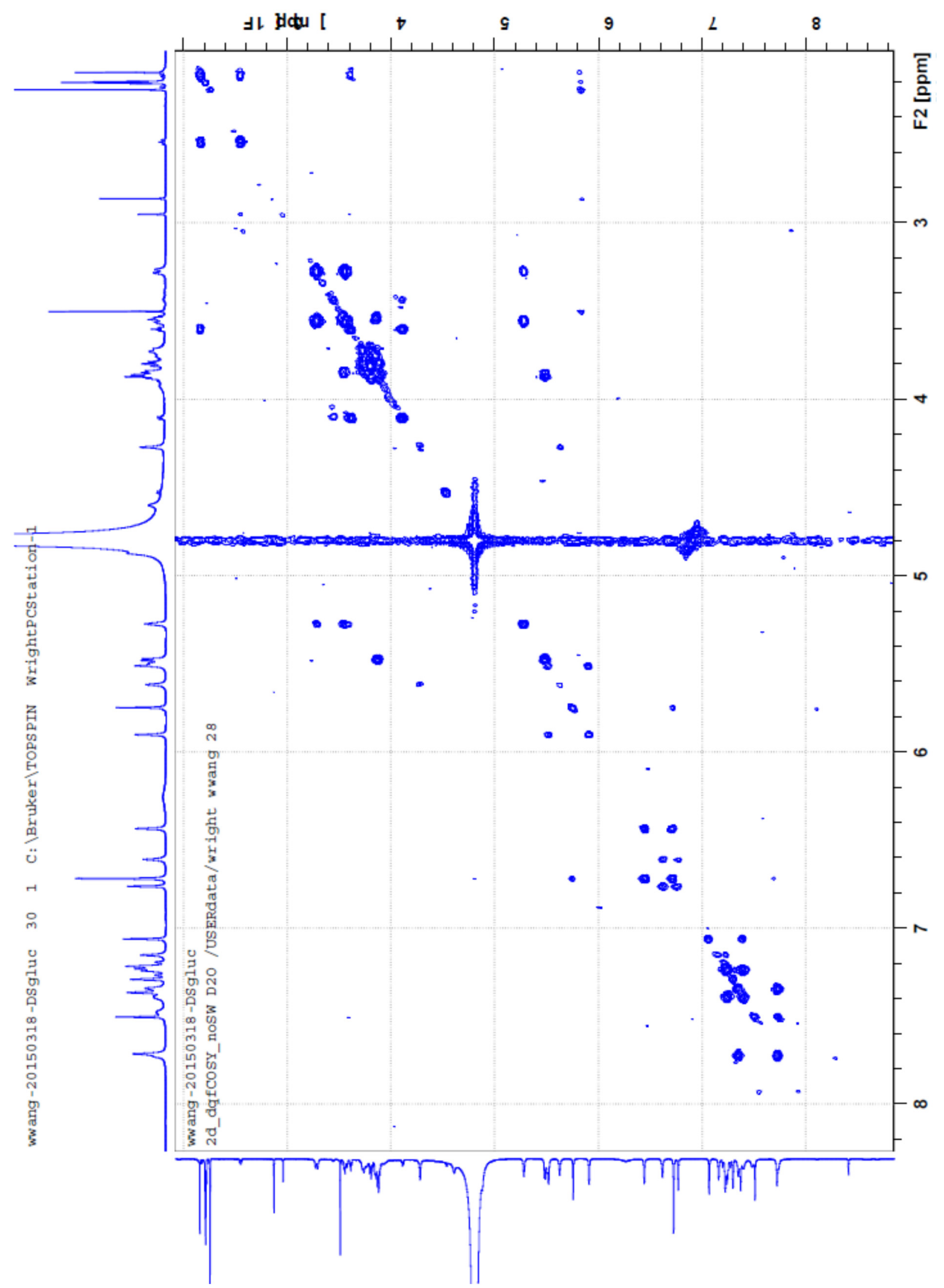

Figure $\mathrm{S} 16 .{ }^{1} \mathrm{H}-{ }^{1} \mathrm{H}$ COSY of compound $2 \mathrm{e}$ in $\mathrm{D}_{2} \mathrm{O}: \mathrm{ACN}-\mathrm{d}_{3}(3: 1, \mathrm{v} / \mathrm{v})$. 


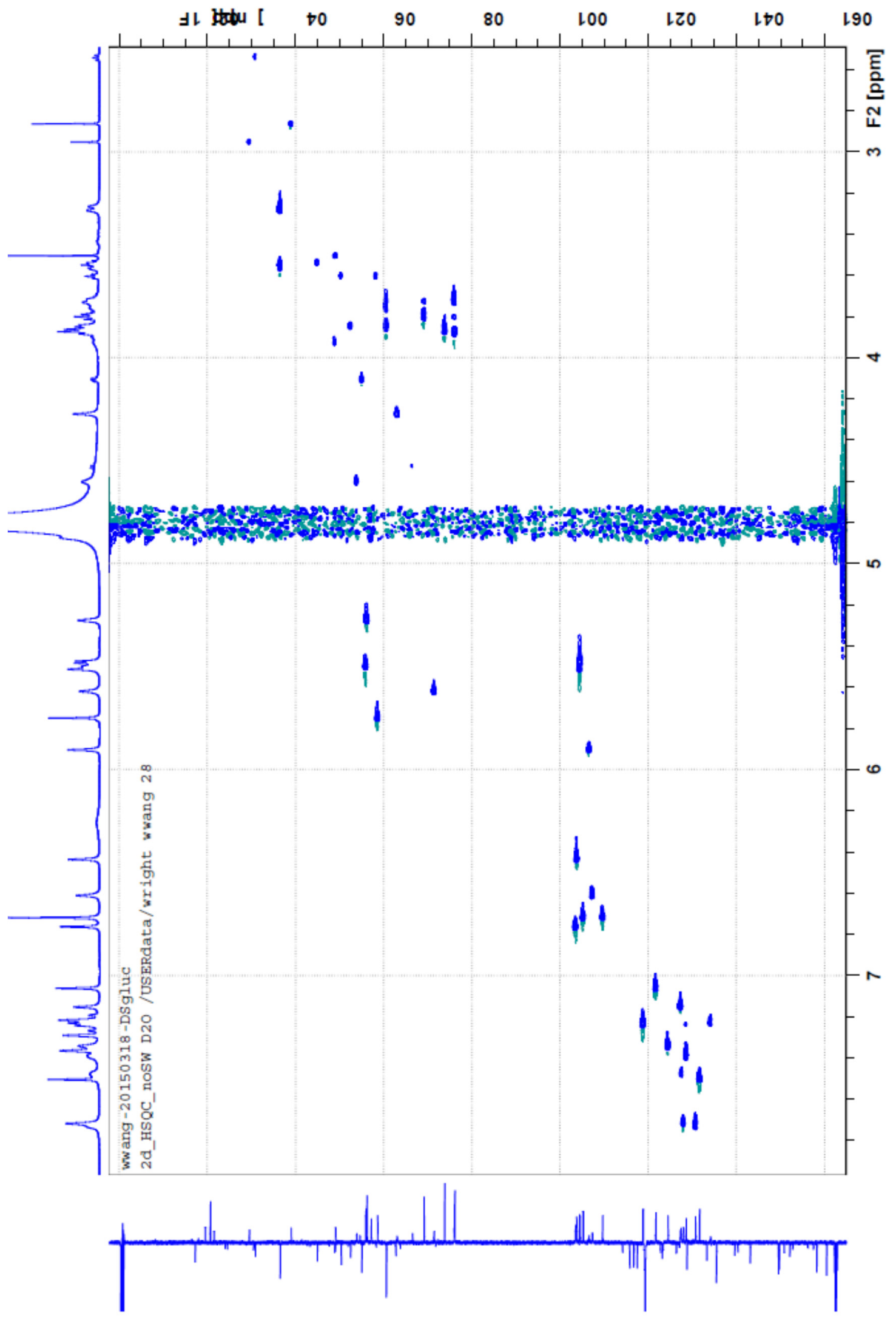

Figure $\mathrm{S} 17 . \mathrm{HSQC}$ of compound $\mathbf{2 e}$ in $\mathrm{D}_{2} \mathrm{O}: \mathrm{ACN}-\mathrm{d}_{3}(3: 1, \mathrm{v} / \mathrm{v})$. 


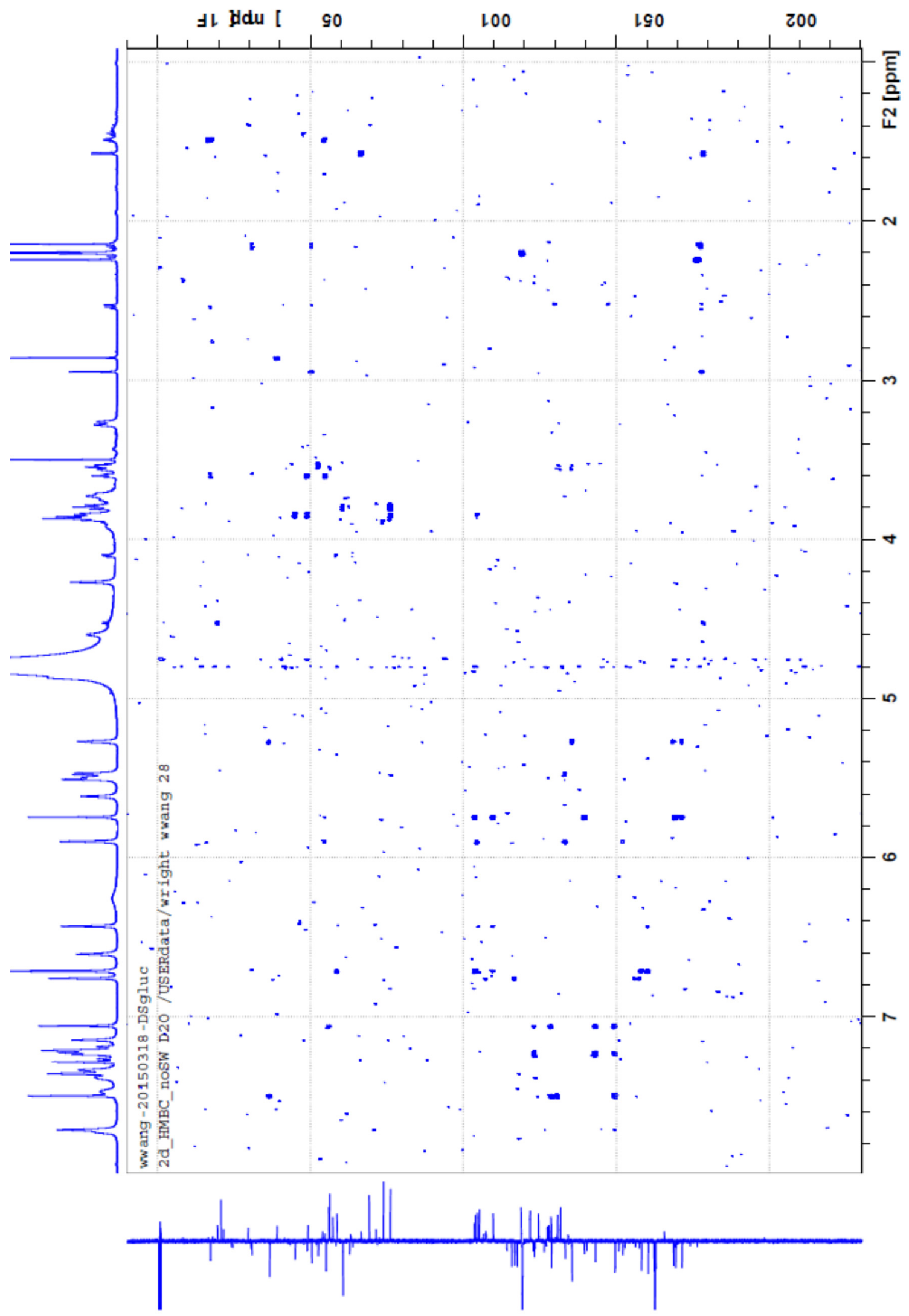

Figure $\mathrm{S} 18$. $\mathrm{HMBC}$ of compound $2 \mathbf{e}$ in $\mathrm{D}_{2} \mathrm{O}: \mathrm{ACN}-\mathrm{d}_{3}(3: 1, \mathrm{v} / \mathrm{v})$. 


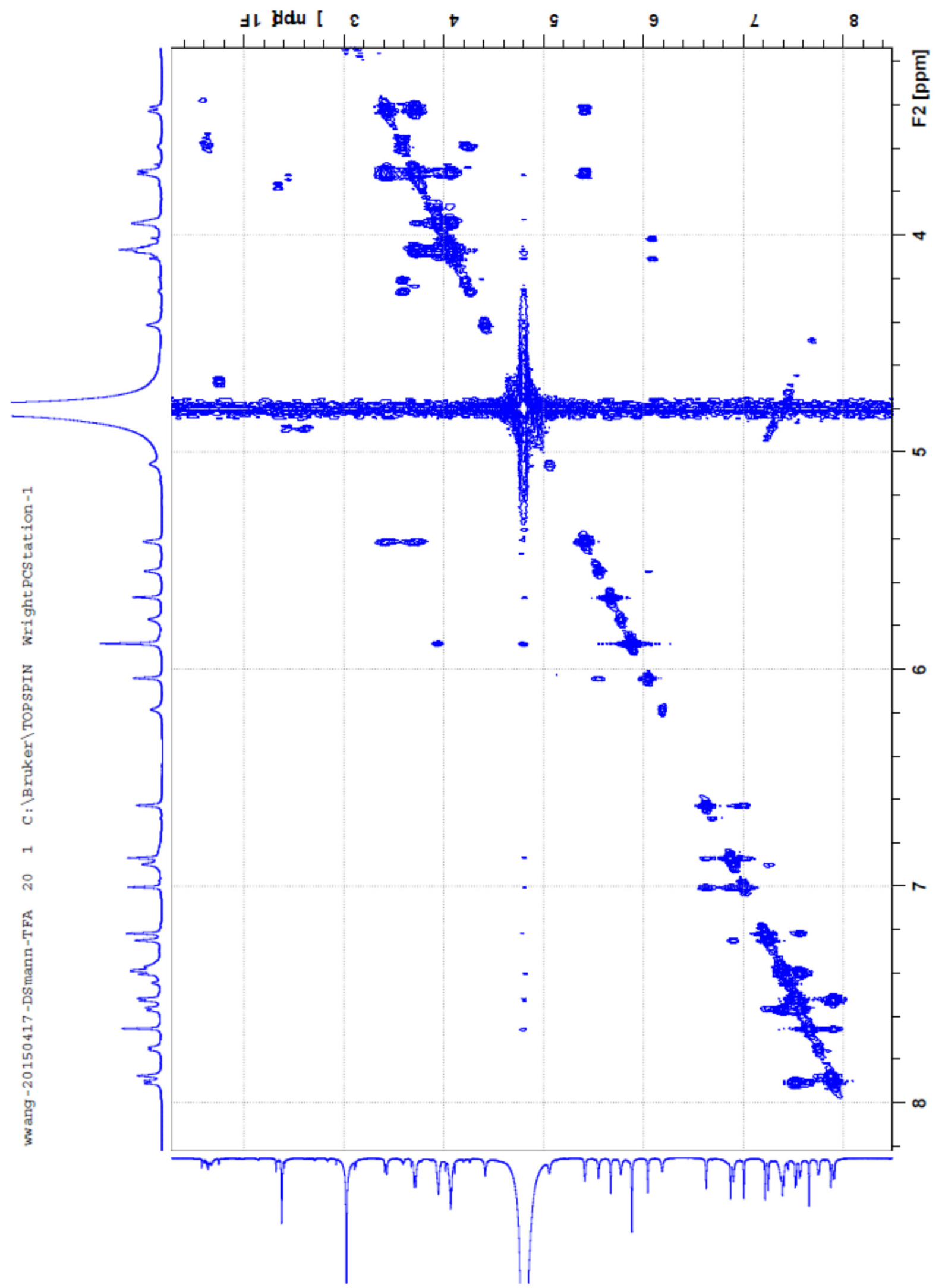

Figure S19. ${ }^{1} \mathrm{H}-{ }^{1} \mathrm{H}$ COSY of compound $2 \mathrm{f}$ in $\mathrm{D}_{2} \mathrm{O}: \mathrm{ACN}-\mathrm{d}_{3}(3: 1, \mathrm{v} / \mathrm{v})$. 


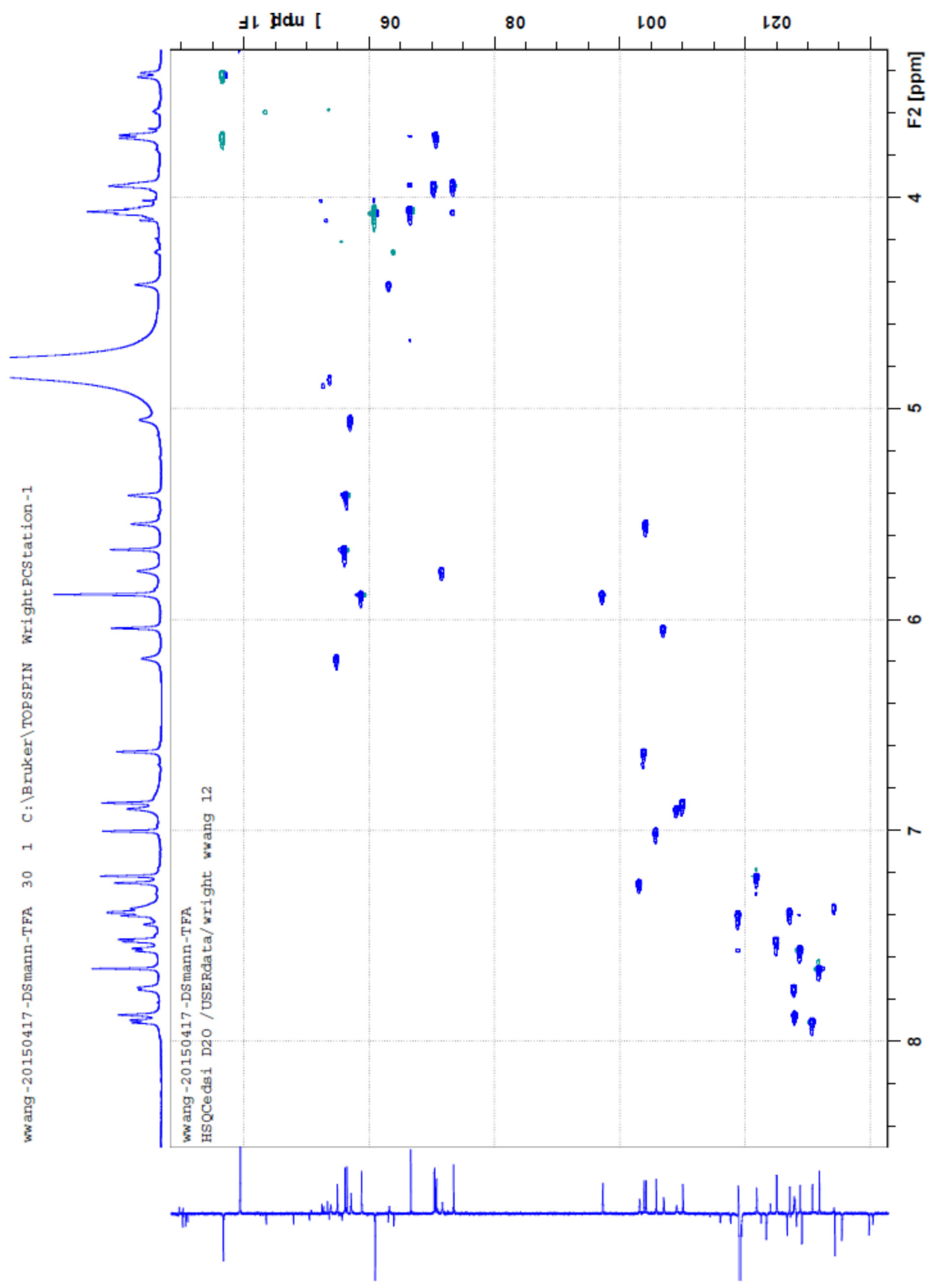

Figure S20. HSQC of compound $2 \mathbf{f}$ in $\mathrm{D}_{2} \mathrm{O}: \mathrm{ACN}-\mathrm{d}_{3}(3: 1, \mathrm{v} / \mathrm{v})$. 


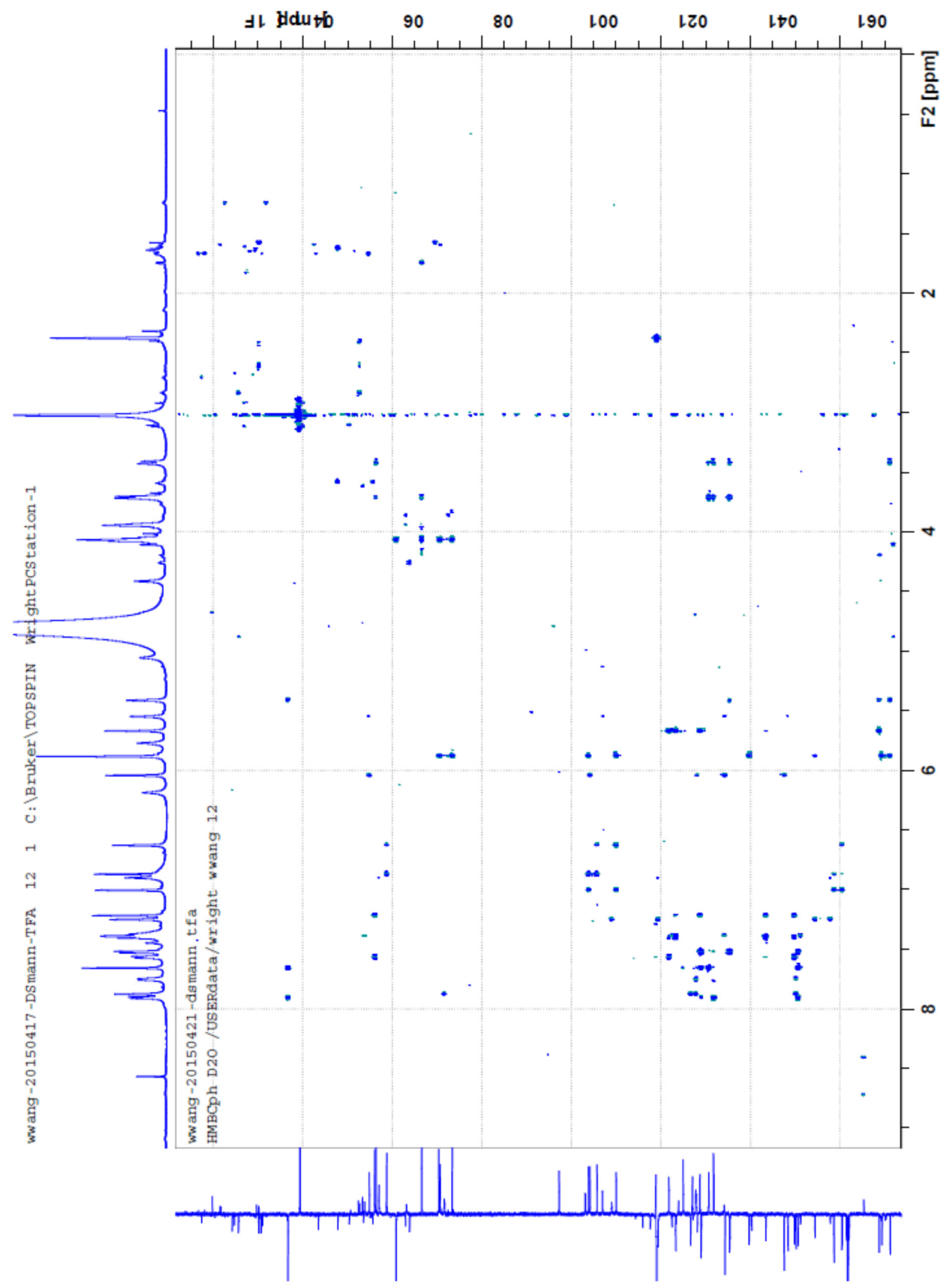

Figure $\mathrm{S} 21$. HMBC of compound $2 \mathrm{f}$ in $\mathrm{D}_{2} \mathrm{O}: \mathrm{ACN}-\mathrm{d}_{3}(3: 1, \mathrm{v} / \mathrm{v})$. 


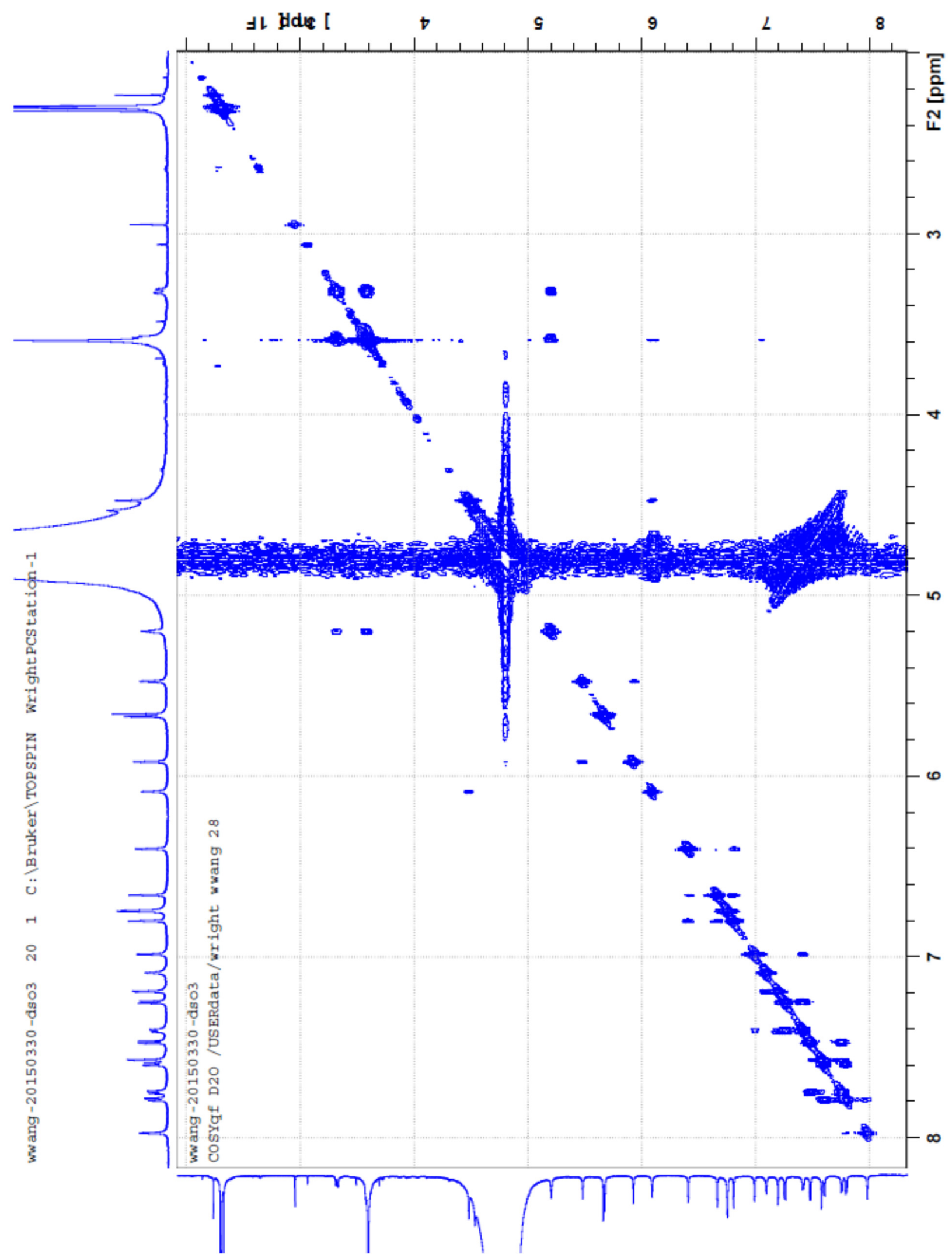

Figure S22. ${ }^{1} \mathrm{H}-{ }^{1} \mathrm{H}$ COSY of compound $\mathbf{2 g}$ in $\mathrm{D}_{2} \mathrm{O}: \mathrm{ACN}-\mathrm{d}_{3}(3: 1, \mathrm{v} / \mathrm{v})$. 


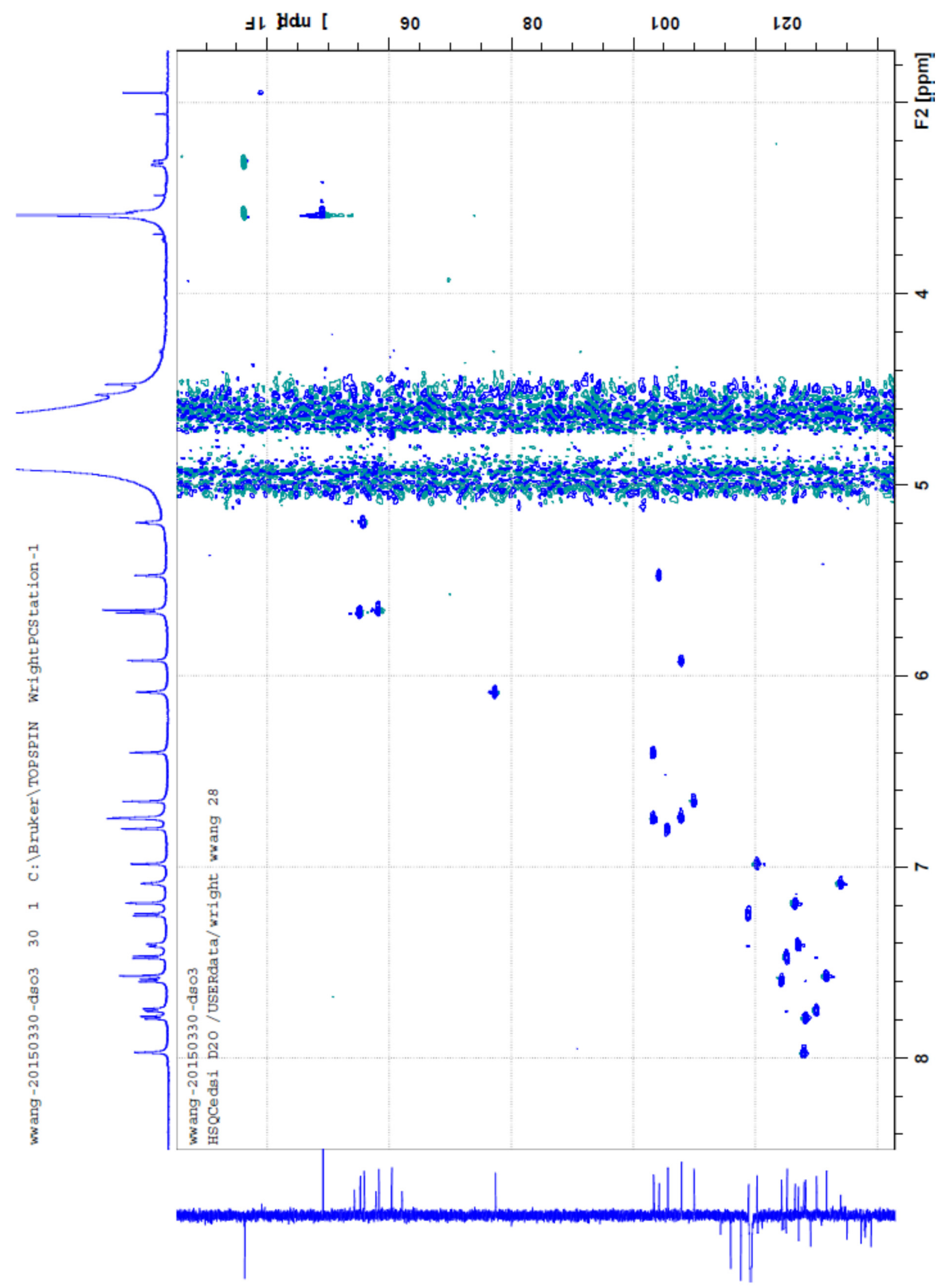

Figure S23. HSQC of compound $\mathbf{2} \mathbf{g}$ in $\mathrm{D}_{2} \mathrm{O}: \mathrm{ACN}-\mathrm{d}_{3}(3: 1, v / v)$. 


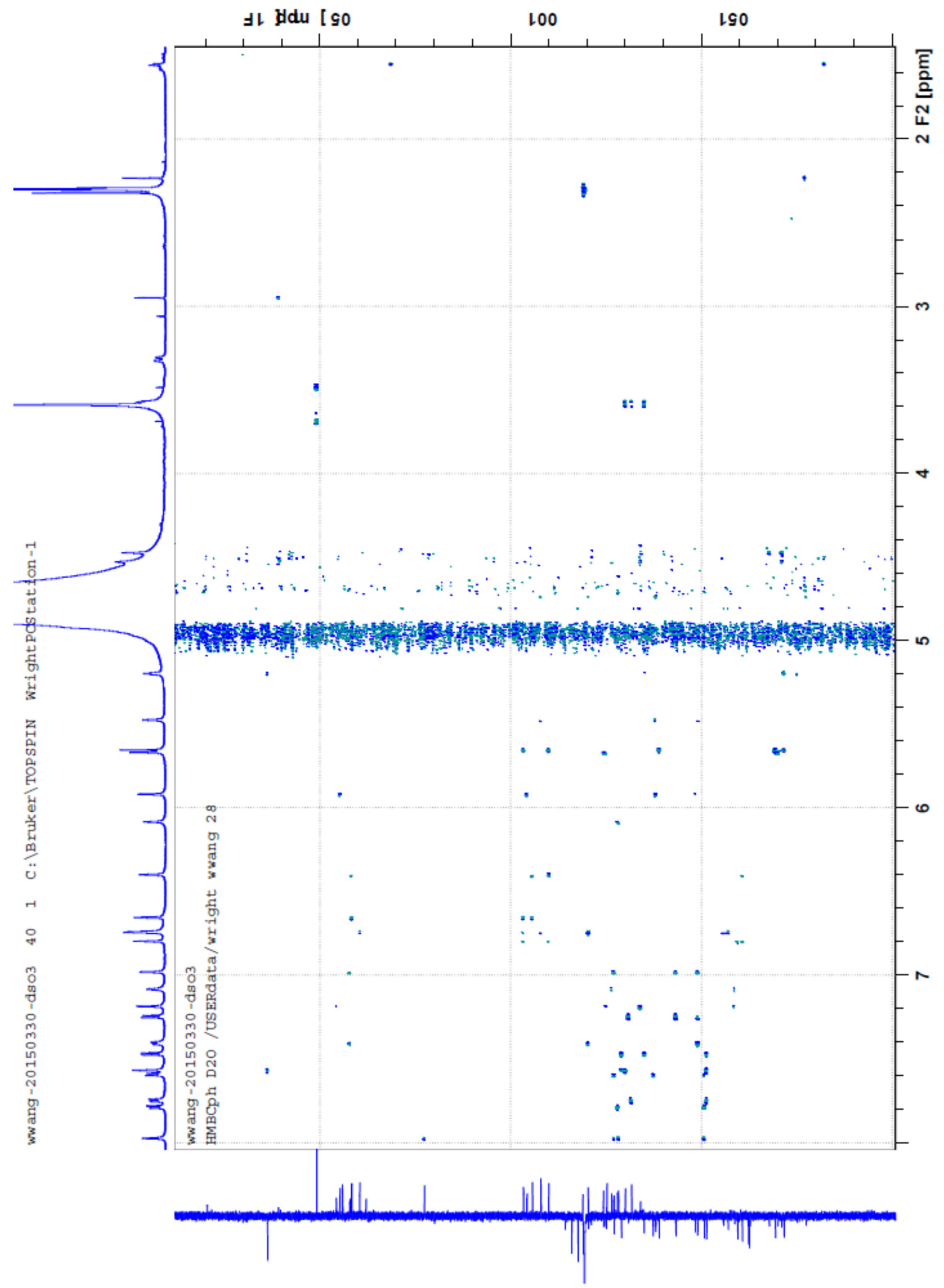

Figure S24. HMBC of compound $\mathbf{2 g}$ in $\mathrm{D}_{2} \mathrm{O}: \mathrm{ACN}-\mathrm{d}_{3}(3: 1, \mathrm{v} / \mathrm{v})$. 


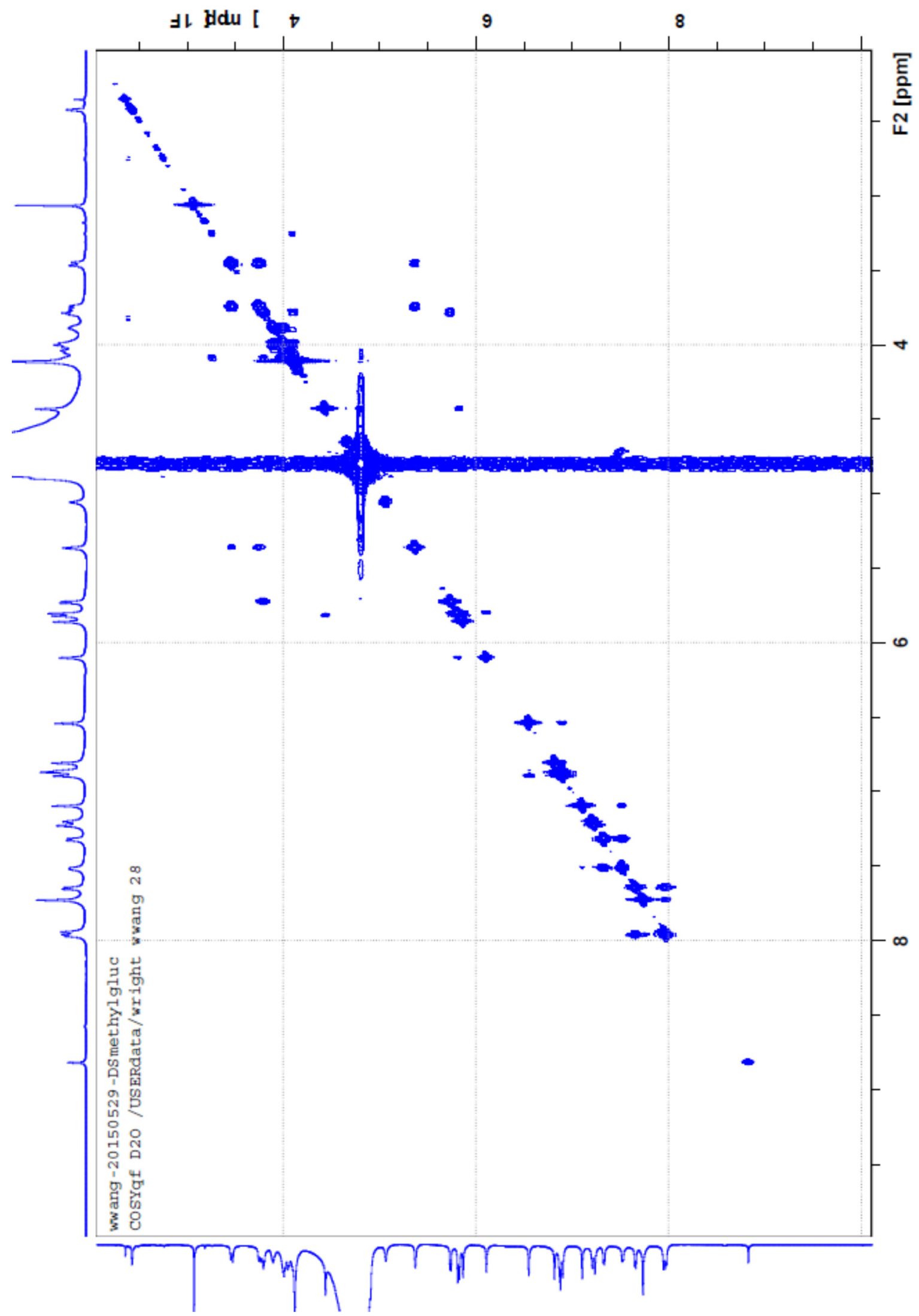

Figure S25. ${ }^{1} \mathrm{H}-{ }^{1} \mathrm{H}$ COSY of compound $2 \mathrm{~h}$ in $\mathrm{D}_{2} \mathrm{O}: \mathrm{ACN}-\mathrm{d}_{3}(3: 1, \mathrm{v} / \mathrm{v})$. 


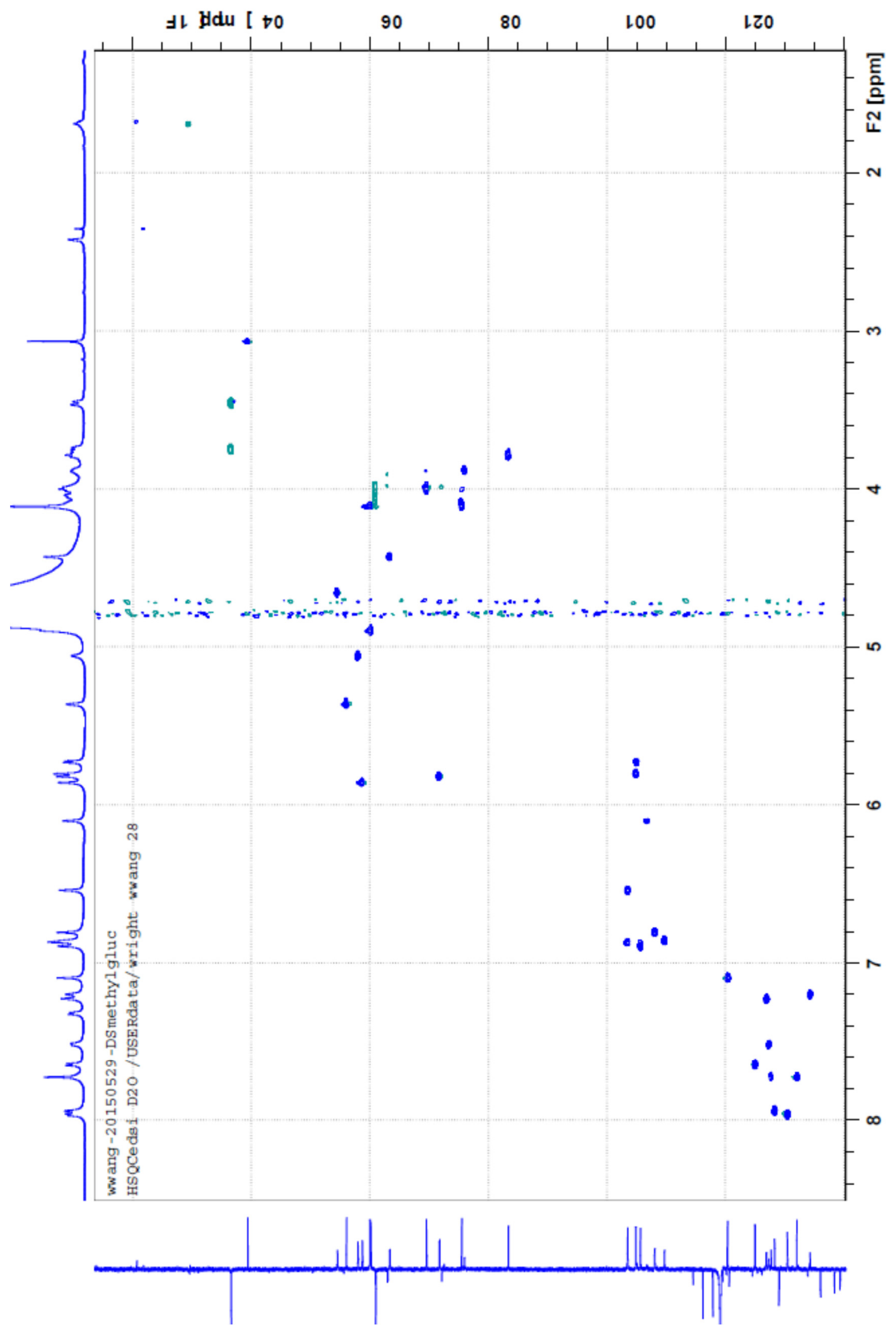

Figure S26. $\mathrm{HSQC}$ of compound $\mathbf{2 h}$ in $\mathrm{D}_{2} \mathrm{O}: \mathrm{ACN}-\mathrm{d}_{3}(3: 1, \mathrm{v} / \mathrm{v})$. 


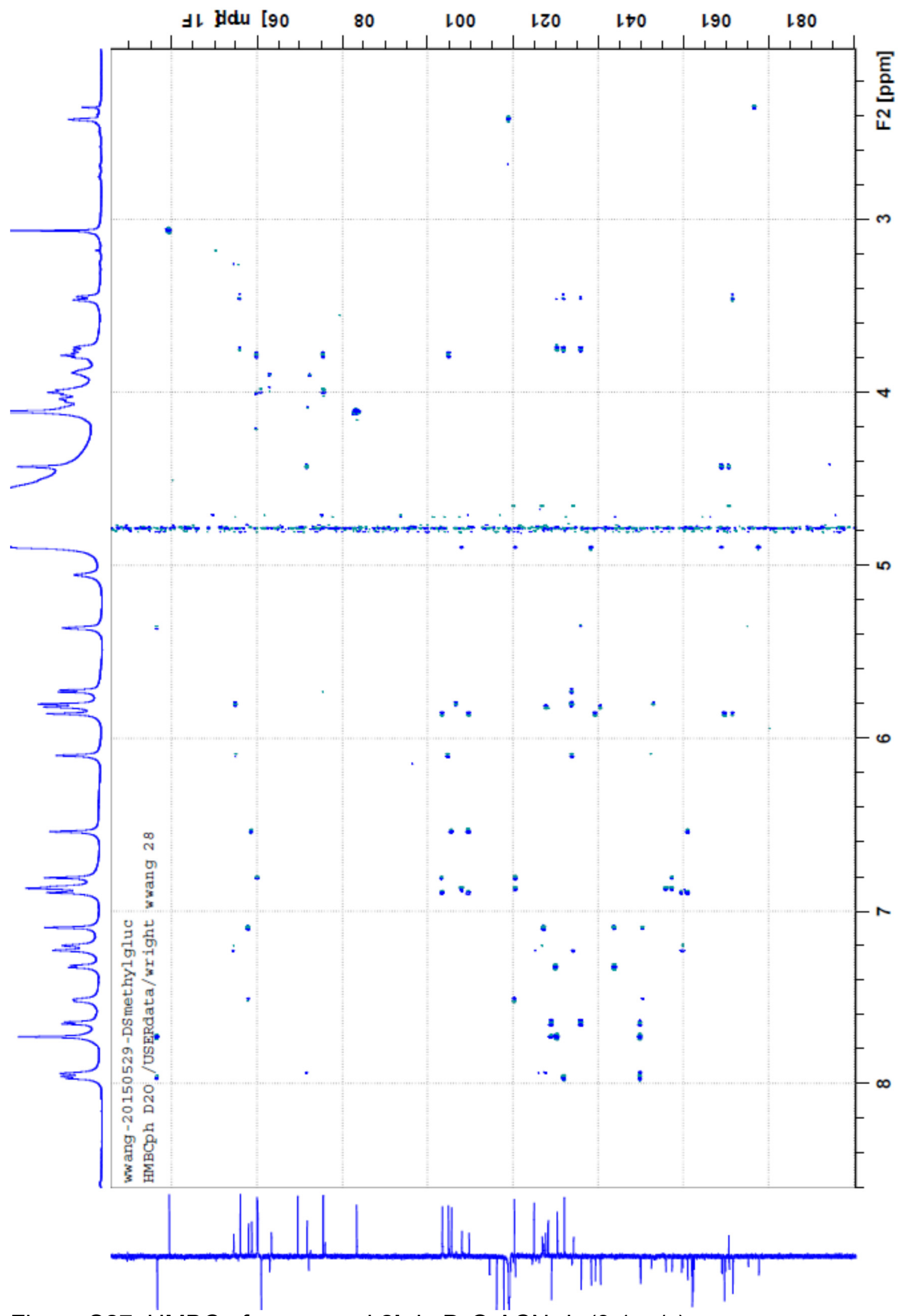

Figure $\mathrm{S} 27$. $\mathrm{HMBC}$ of compound $\mathbf{2} \mathbf{h}$ in $\mathrm{D}_{2} \mathrm{O}: \mathrm{ACN}-\mathrm{d}_{3}(3: 1, \mathrm{v} / \mathrm{v})$. 
Figure S28. ${ }^{1} \mathrm{H}$ and ${ }^{13} \mathrm{C}$ assignments for 2 in $\mathrm{D}_{2} \mathrm{O}: \mathrm{ACN}-\mathrm{d}_{3}(3: 1, \mathrm{v} / \mathrm{v})$.

\begin{tabular}{|c|c|c|c|c|c|}
\hline Pos & $\begin{array}{c}\delta^{1} \mathrm{H} \\
\text { (ppm) }\end{array}$ & $\begin{array}{l}\delta^{13} C \\
\text { (ppm) }\end{array}$ & Pos & $\begin{array}{c}\delta^{1} \mathrm{H} \\
(\mathrm{ppm})\end{array}$ & $\delta^{13} \mathrm{C}(\mathrm{ppm})$ \\
\hline $1 a$ & & 131.2 & $6 a$ & & 140.0 \\
\hline $1 b$ & 7.05 & 120.3 & $6 b$ & 7.88 & 128.0 \\
\hline $1 c$ & & 143.4 & $6 c$ & & 126.5 \\
\hline $1 d$ & & 148.7 & $6 d$ & & 150.3 \\
\hline $1 e$ & 7.31 & 118.9 & $6 e$ & 7.09 & 124.0 \\
\hline $1 f$ & 7.47 & 127.1 & $6 f$ & 7.74 & 127.5 \\
\hline $2 a$ & & 135.2 & $7 a$ & & 138.5 \\
\hline $2 b$ & 7.63 & 131.8 & $7 b$ & & 119.5 \\
\hline $2 c$ & & 129.1 & $7 c$ & & 155.9 \\
\hline $2 d$ & & 150.8 & $7 d$ & 6.80 & 103.2 \\
\hline $2 e$ & 7.54 & 125.1 & $7 e$ & & 157.3 \\
\hline $2 f$ & 7.82 & 130.1 & $7 f$ & 6.76 & 108.2 \\
\hline $3 a$ & & 139.2 & C1 & & 174.9 \\
\hline $3 b$ & 6.76 & 109.7 & C2 & & 171.6 \\
\hline $3 c$ & & 160.7 & C3 & & 169.4 \\
\hline $3 d$ & 6.84 & 105.6 & C4 & & 170.2 \\
\hline $3 e$ & & 158.9 & C5 & & 170.6 \\
\hline $3 f$ & 6.47 & 103.5 & C6 & & 168.8 \\
\hline $4 a$ & & 126.6 & $\mathrm{C} 7$ & & 177.4 \\
\hline $4 b$ & 5.98 & 107.1 & $\mathrm{X} 1$ & 4.98 & 57.8 \\
\hline $4 c$ & & 148.0 & X2 & 5.27 & 55.9 \\
\hline $4 d$ & & 136.2 & X3 & 5.75 & 58.4 \\
\hline $4 e$ & & 148.9 & X4 & 5.98 & 55.0 \\
\hline $4 f$ & 5.56 & 104.2 & $\times 5$ & 4.62 & 54.3 \\
\hline $5 a$ & & 122.9 & X6 & 4.33 & 63.3 \\
\hline $5 b$ & 7.18 & 134.4 & X7 & 4.83 & 59.9 \\
\hline $5 c$ & & 124.5 & Z2 & 3.36 & 36.3 \\
\hline $5 d$ & & 156.4 & Z2' & 3.65 & 36.3 \\
\hline $5 e$ & & 124.3 & Z6 & 5.74 & 71.7 \\
\hline $5 f$ & 7.23 & 126.9 & & & \\
\hline
\end{tabular}

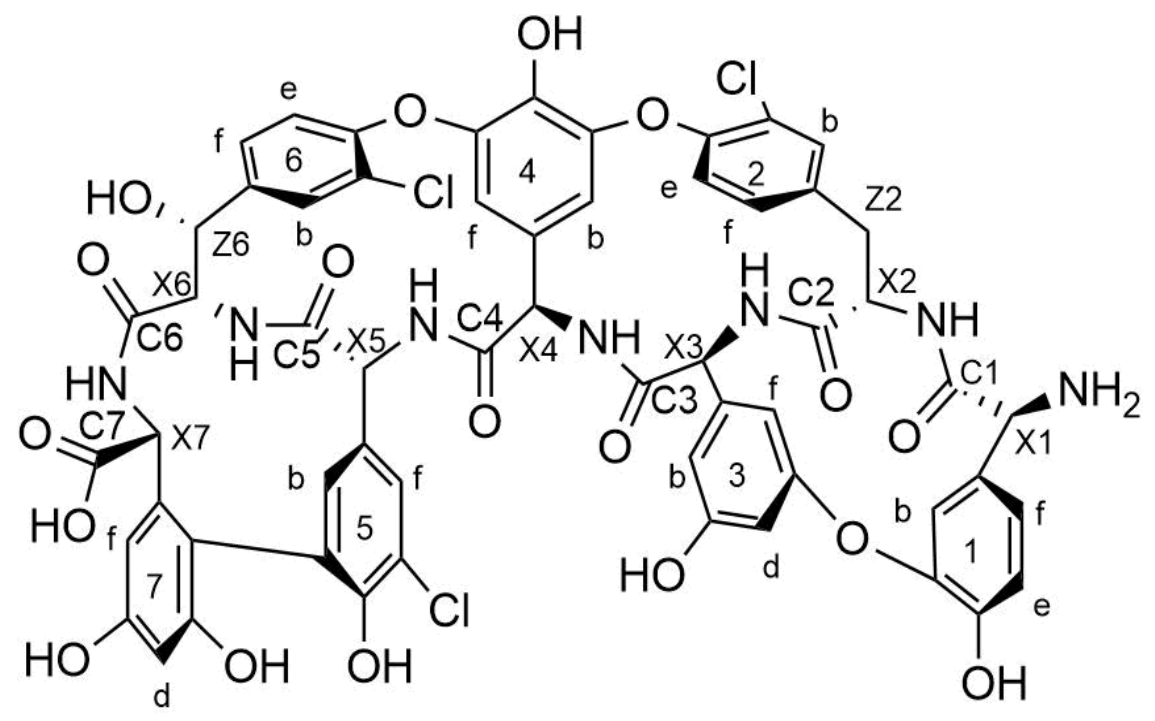


Figure S29a. Key correlations and ${ }^{1} \mathrm{H}$ and ${ }^{13} \mathrm{C}$ assignments for $2 \mathrm{a}$ in $\mathrm{D}_{2} \mathrm{O}: \mathrm{ACN}-\mathrm{d}_{3}(3: 1, \mathrm{v} / \mathrm{v})$.

\begin{tabular}{lcc}
\hline Assignment & $\begin{array}{c}\boldsymbol{\delta}{ }^{1} \mathbf{H} \\
(\mathbf{p p m})\end{array}$ & $\mathbf{\delta}^{13} \mathbf{C}(\mathbf{p p m})$ \\
\hline $7 \mathrm{~b}$ & & 116.8 \\
$7 \mathrm{~d}$ & 6.89 & 103.5 \\
$7 \mathrm{f}$ & 6.58 & 107.2 \\
X7 & 5.04 & 57.0 \\
C1 & & 172.8 \\
C1-OMe & 4.18 & 53.3 \\
\hline
\end{tabular}

Figure S29b. Key correlations and ${ }^{1} \mathrm{H}$ and ${ }^{13} \mathrm{C}$ assignments $\mathbf{2 b}$ in $\mathrm{D}_{2} \mathrm{O}: \mathrm{ACN}-\mathrm{d}_{3}(3: 1, \mathrm{v} / \mathrm{v})$.

\begin{tabular}{lcc}
\hline Assignment & $\begin{array}{c}\boldsymbol{\delta}^{1} \mathbf{H} \\
(\mathbf{p p m})\end{array}$ & $\mathbf{\delta}^{{ }^{13} \mathbf{C}^{*}(\mathbf{p p m})}$ \\
\hline 3b & 6.98 & 109.1 \\
3c & & 158.8 \\
3d & 2.60 & 115.2 \\
$3 \mathrm{~d}-\mathrm{CH}_{3}$ & & 8.0 \\
3e & 6.72 & 156.8 \\
$3 \mathrm{f}$ & 5.89 & 104.3 \\
X3 & 58.3 \\
\hline${ }^{*}$ predicted from HSQC and HMBC spectra \\
\hline
\end{tabular}

Figure S29c. Key correlations and ${ }^{1} \mathrm{H}$ and ${ }^{13} \mathrm{C}$ assignments for $\mathbf{2 d}$ in DMSO-d6.

\begin{tabular}{lcc}
\hline Assignment & $\begin{array}{c}\mathbf{\delta}{ }^{\mathbf{1}} \mathbf{H} \\
(\mathbf{p p m})\end{array}$ & $\mathbf{\delta}^{\mathbf{1 3}} \mathbf{C}(\mathbf{p p m})$ \\
\hline 4b & 5.49 & 107.9 \\
4c & & 152.0 \\
4d & & 133.4 \\
4e & & 152.7 \\
4f & 5.10 & 104.9 \\
X4 & 5.43 & 55.0 \\
G1 & 5.25 & 103.1 \\
G2 & 3.70 & 56.9 \\
G3 & 3.62 & 73.8 \\
G4 & 3.20 & 71.0 \\
G5 & 3.21 & 77.5 \\
G6 & 3.52 & 61.7 \\
& 3.69 & 61.7 \\
G2-NH & 7.91 & \\
G7 & & 169.9 \\
G8 & 1.72 & 23.7 \\
\hline
\end{tabular}

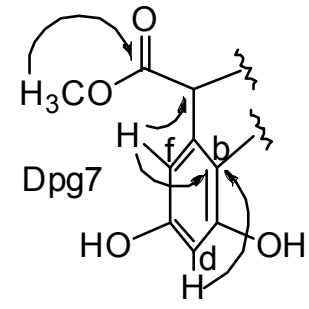

$\checkmark$ Key HMBC correlations

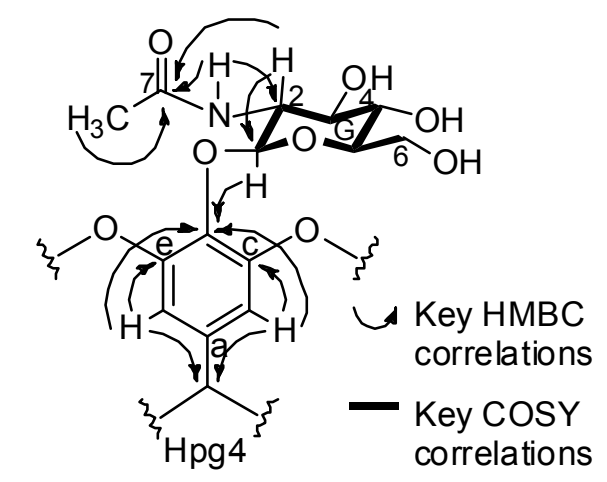


Figure S29d. Key correlations and ${ }^{1} \mathrm{H}$ and ${ }^{13} \mathrm{C}$

\begin{tabular}{|c|c|c|}
\hline Assignment & $\begin{array}{r}\delta^{1} \mathrm{H} \\
(\mathrm{ppm})\end{array}$ & $\delta^{13} \mathrm{C}$ (ppm) \\
\hline $4 c$ & & 151.9 \\
\hline $4 d$ & & 133.1 \\
\hline $4 \mathrm{e}$ & & 152.9 \\
\hline$X 4$ & 4.11 & 54.6 \\
\hline G1 & 5.48 & 104.5 \\
\hline $\mathrm{G} 2$ & 3.88 & 76.1 \\
\hline G3 & 3.86 & 73.8 \\
\hline G4 & 3.80 & 69.1 \\
\hline G5 & 3.72 & 75.9 \\
\hline \multirow[t]{2}{*}{ G6 } & 3.74 & 60.6 \\
\hline & 3.84 & 60.6 \\
\hline
\end{tabular}

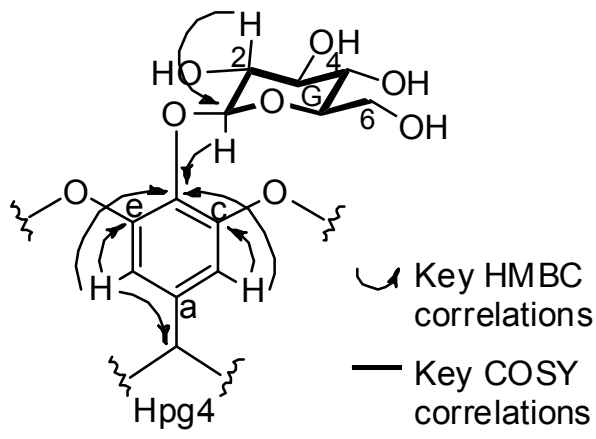

Figure S29e. Selected ${ }^{1} \mathrm{H}$ and ${ }^{13} \mathrm{C}$ assignments and key correlations for $2 \mathrm{f}$ in $\mathrm{D}_{2} \mathrm{O}: \mathrm{ACN}-\mathrm{d}_{3}(3: 1, \mathrm{v} / \mathrm{v})$.

\begin{tabular}{lcc}
\hline Assignment & $\begin{array}{c}\boldsymbol{\delta}^{\mathbf{1}} \mathbf{H} \\
(\mathbf{p p m})\end{array}$ & $\mathbf{\delta}^{\mathbf{1 3}} \mathbf{C}(\mathbf{p p m})$ \\
\hline 7b & & 119.3 \\
$7 \mathrm{c}$ & & 154.4 \\
$7 \mathrm{~d}$ & 7.25 & 103.2 \\
$7 \mathrm{e}$ & & 157.8 \\
$7 \mathrm{f}$ & 6.90 & 109.0 \\
X7 & 5.06 & 57.0 \\
M1 & 5.88 & 97.3 \\
M2 & 3.94 & 70.2 \\
M3 & 3.95 & 73.4 \\
M4 & 4.06 & 66.7 \\
M5 & 3.72 & 70.6 \\
M6 & 4.01 & 60.8 \\
& 4.07 & 60.8 \\
\hline
\end{tabular}

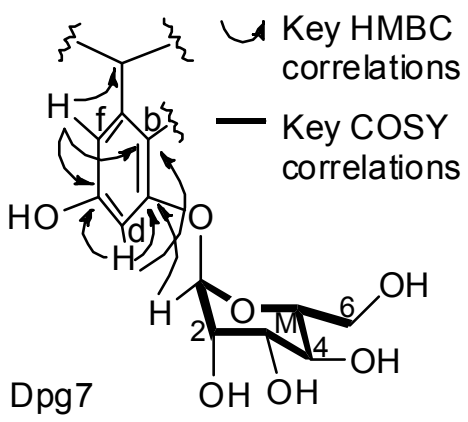

Figure S29f. Key correlations and ${ }^{1} \mathrm{H}$ and ${ }^{13} \mathrm{C}$ assignments for $2 \mathrm{~h}$ in $\mathrm{D}_{2} \mathrm{O}: \mathrm{ACN}-\mathrm{d}_{3}(3: 1, \mathrm{v} / \mathrm{v})$.

\begin{tabular}{lcc}
\hline Assignment & $\begin{array}{c}\mathbf{\delta}^{\mathbf{1}} \mathbf{H} \\
(\mathbf{p p m})\end{array}$ & $\mathbf{\delta}^{\mathbf{1}} \mathbf{C} \mathbf{( p p m )}$ \\
\hline 4c & & 152.5 \\
4d & & 133.8 \\
4e & & 153.1 \\
X4 & 55.1 \\
G1 & 5.73 & 105.0 \\
G2 & 3.79 & 83.4 \\
G2-OMe & 4.11 & 60.1 \\
G3 & 4.10 & 75.5 \\
G4 & 4.00 & 69.5 \\
G5 & 3.88 & 76.0 \\
G6 & 3.99 & 60.9 \\
& 4.04 & 60.9 \\
\hline
\end{tabular}

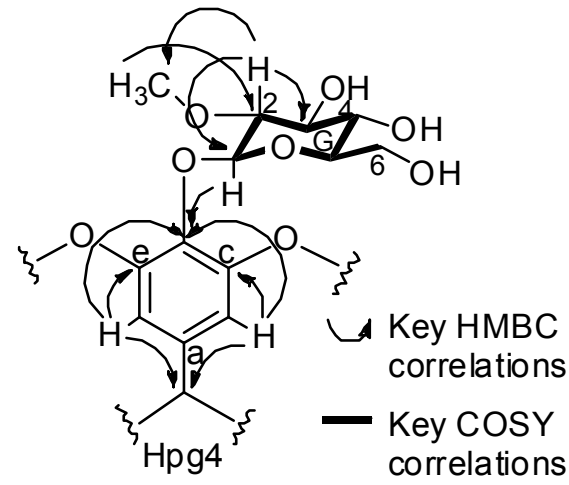




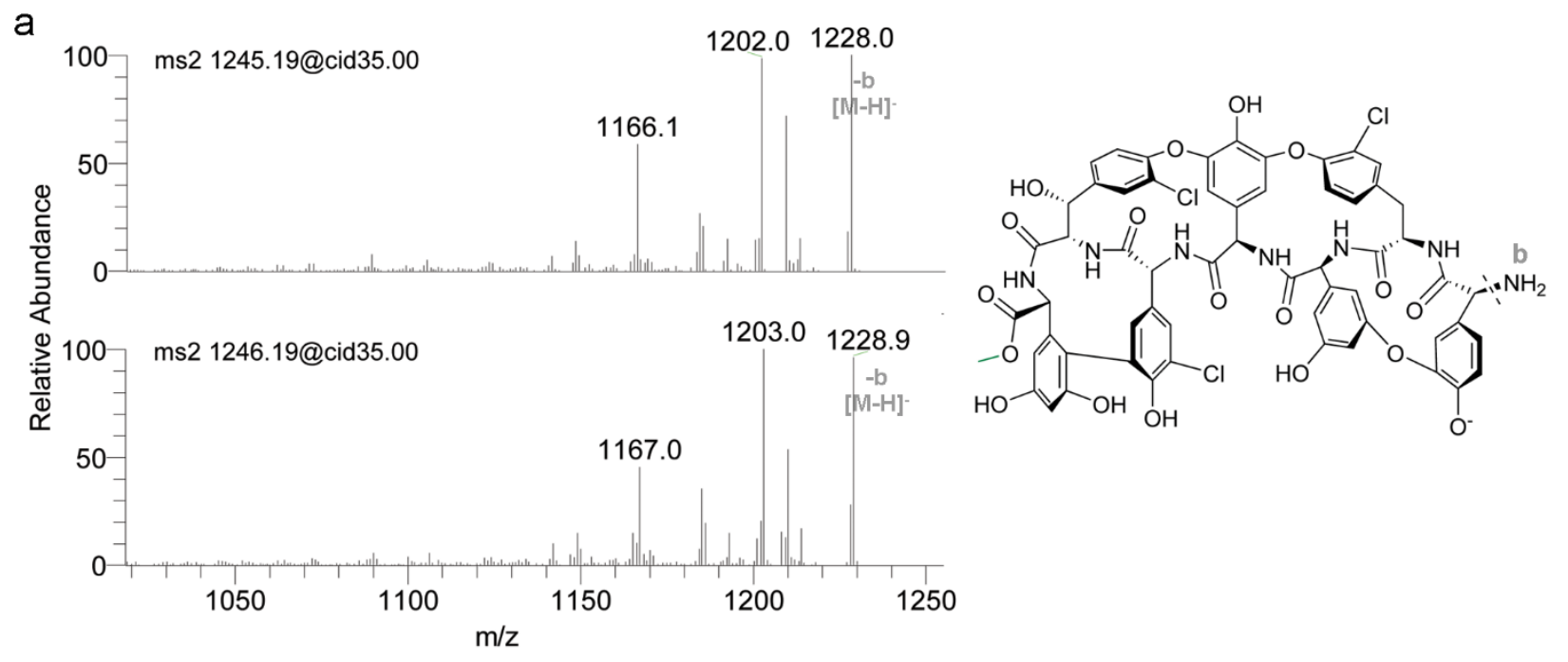

b

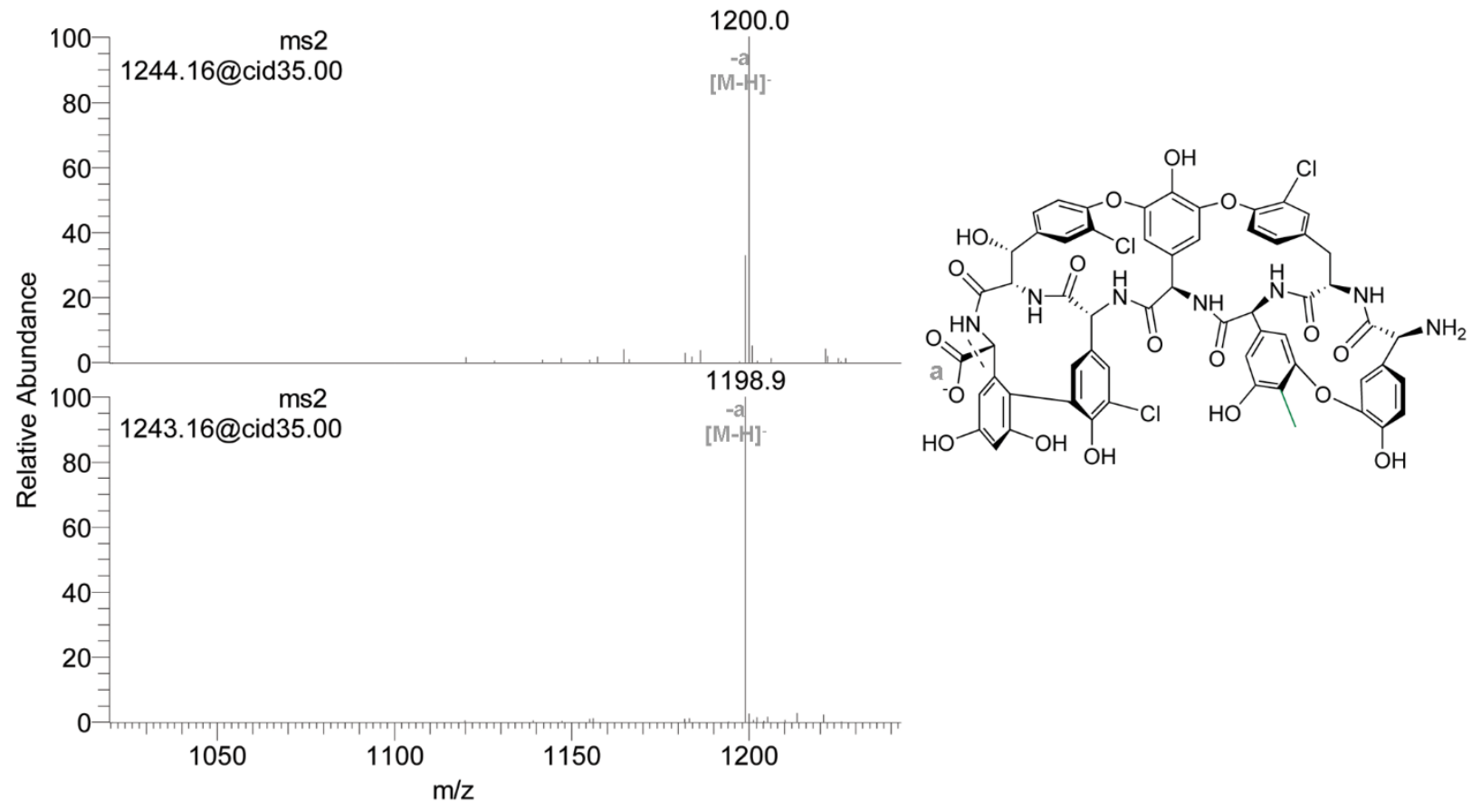

C

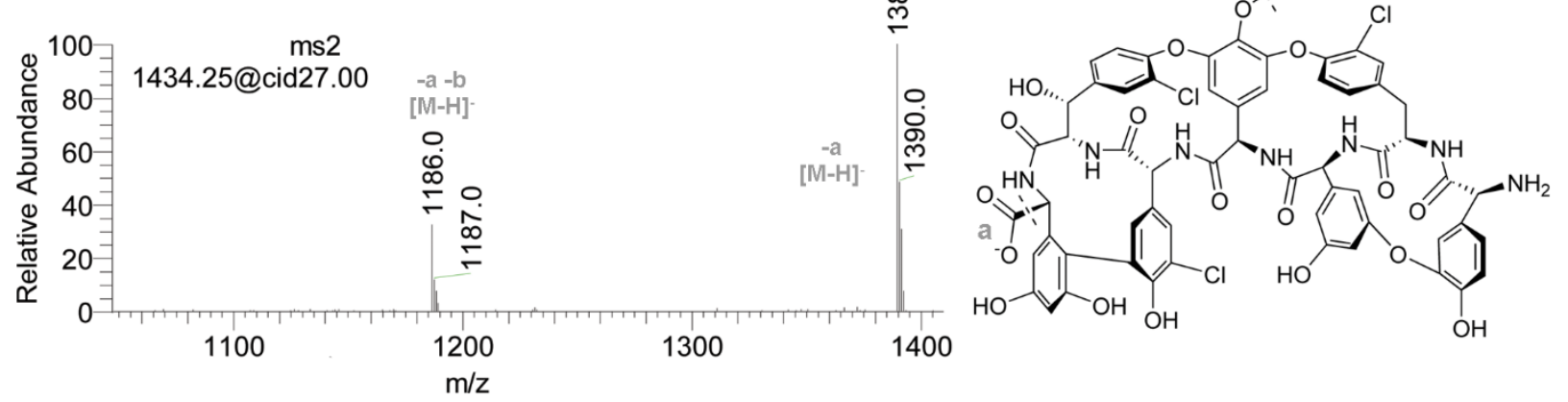



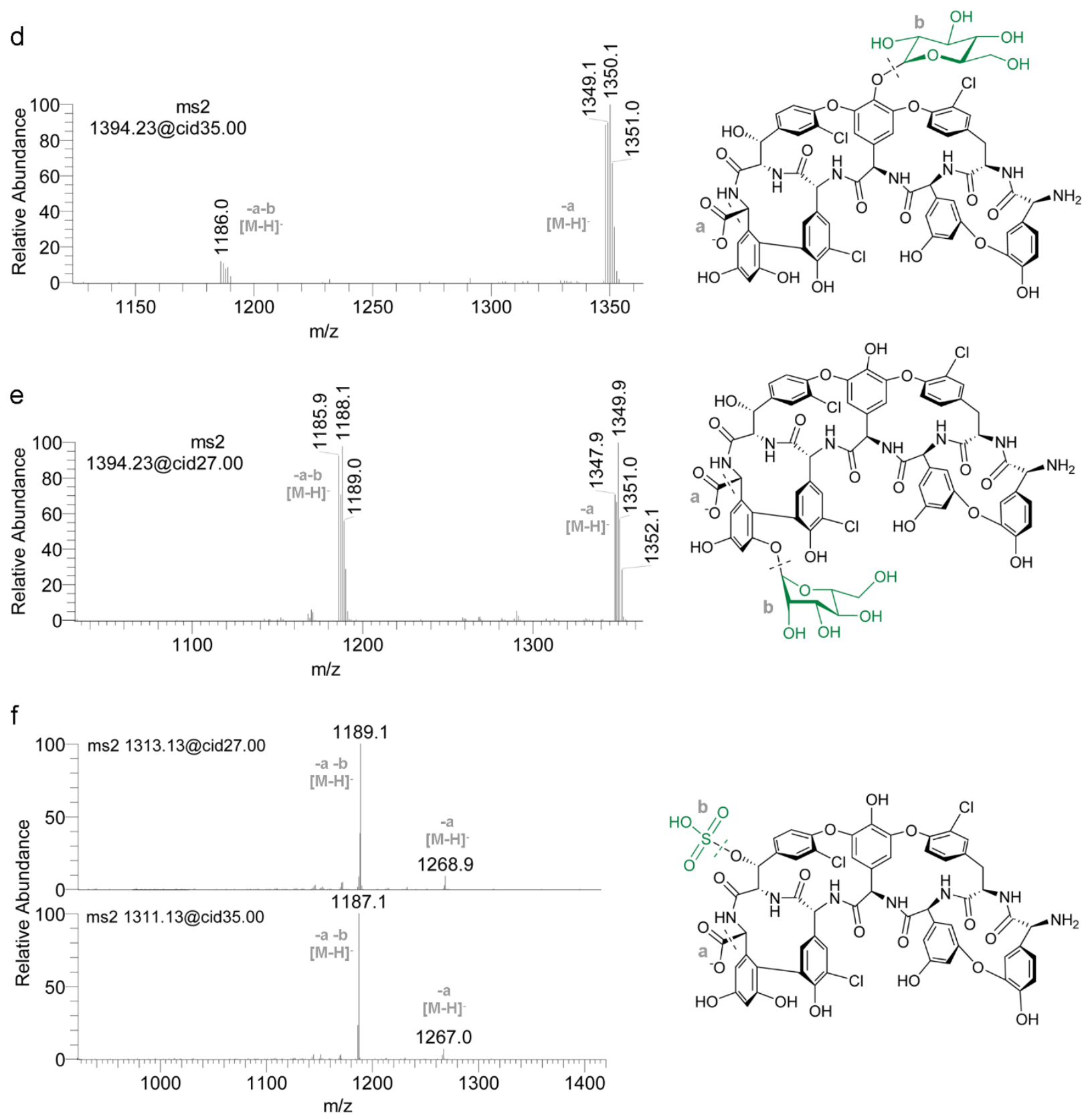

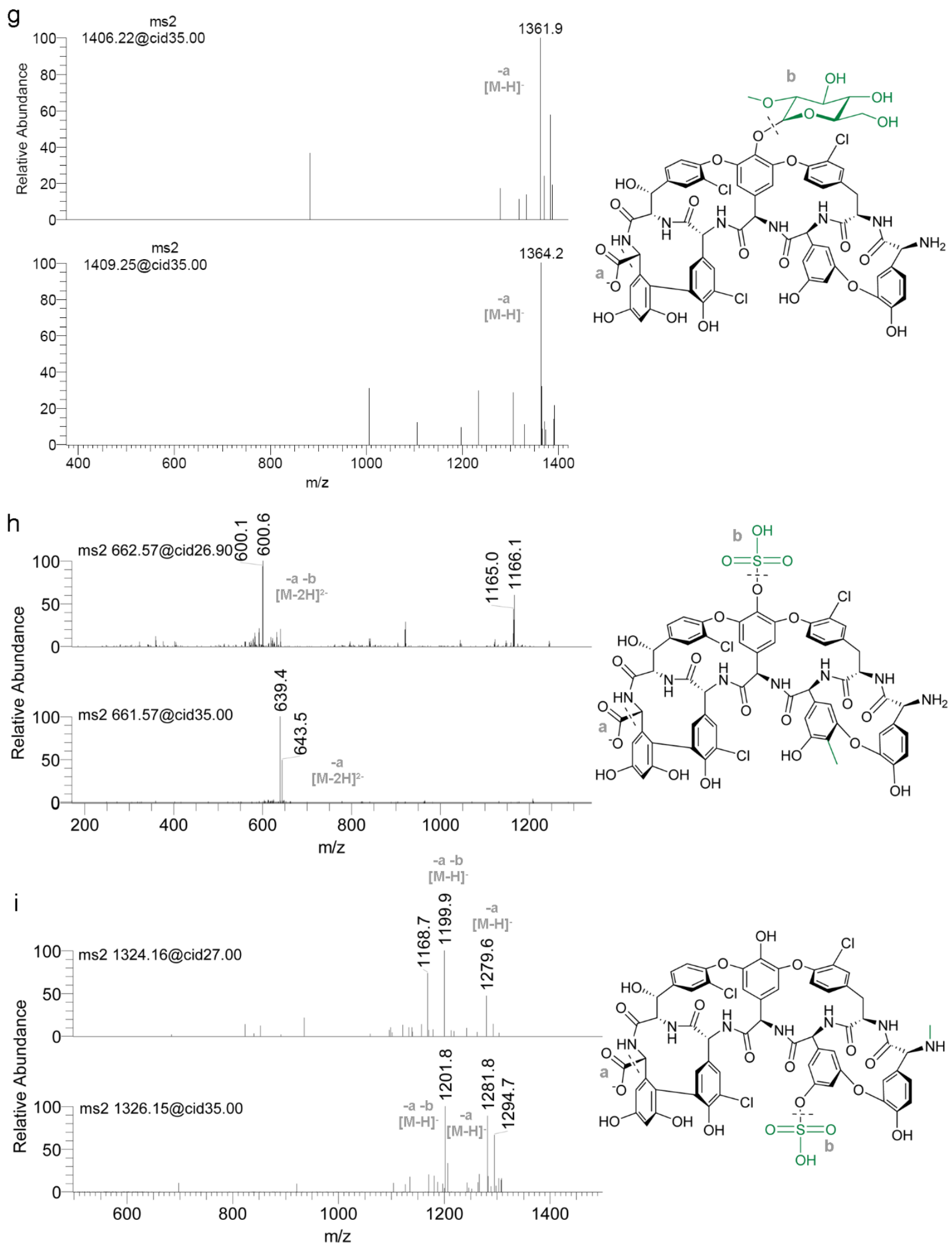

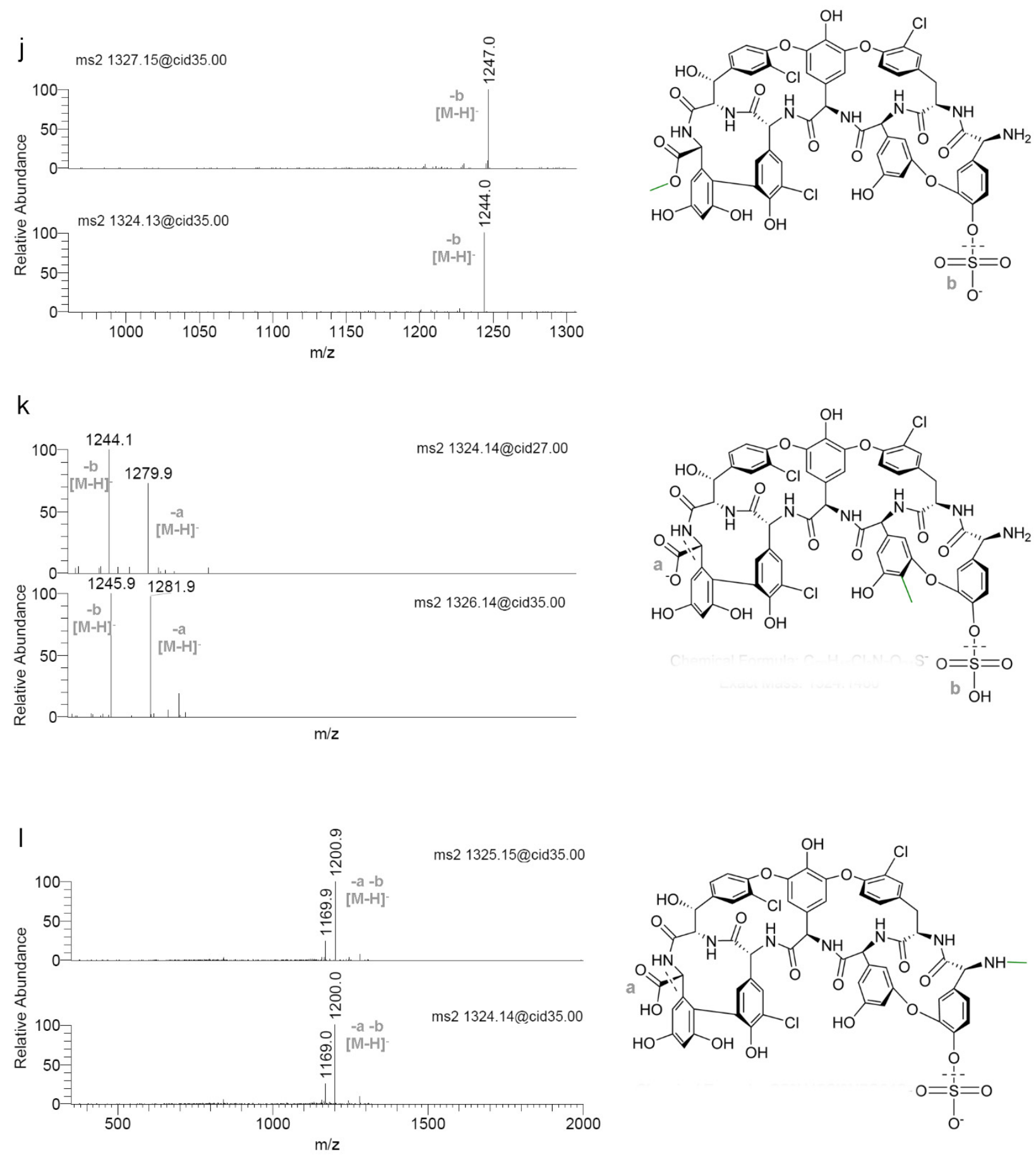

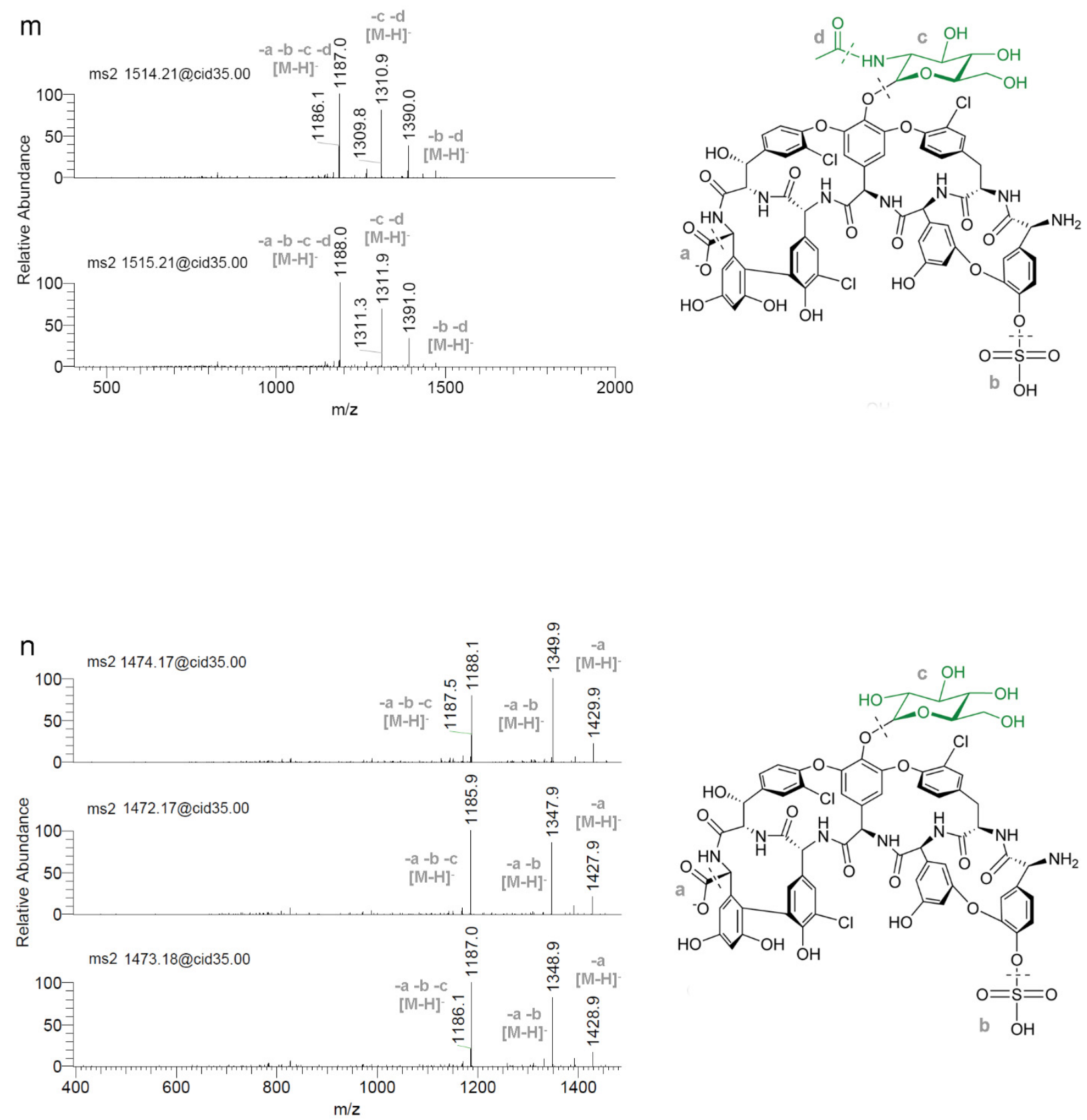

Figure S30. MS/MS fragmentation of novel compounds. Parent ions of various singly [M-H] or doubly $[\mathrm{M}-2 \mathrm{H}]^{2-}$ charged isotopic peaks were fragmented by negative ion ESI-MS/MS at -27 or $-35 \mathrm{eV}$ showing GPA fragmentation patterns similar to those observed previously (24). Fragmentations of novel products

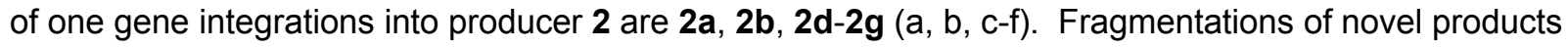
of two gene integrations into producer 2 are $\mathbf{2 h}-\mathbf{2 j}$ ( $\mathrm{g}-\mathrm{i})$. Fragmentations of products of one gene integrations into producer $\mathbf{1}$ are $\mathbf{1 a}-\mathbf{1 e}(\mathrm{j}-\mathrm{n})$. Modifications to the parent scaffold $\mathbf{2}$ or $\mathbf{1}$ are green. 

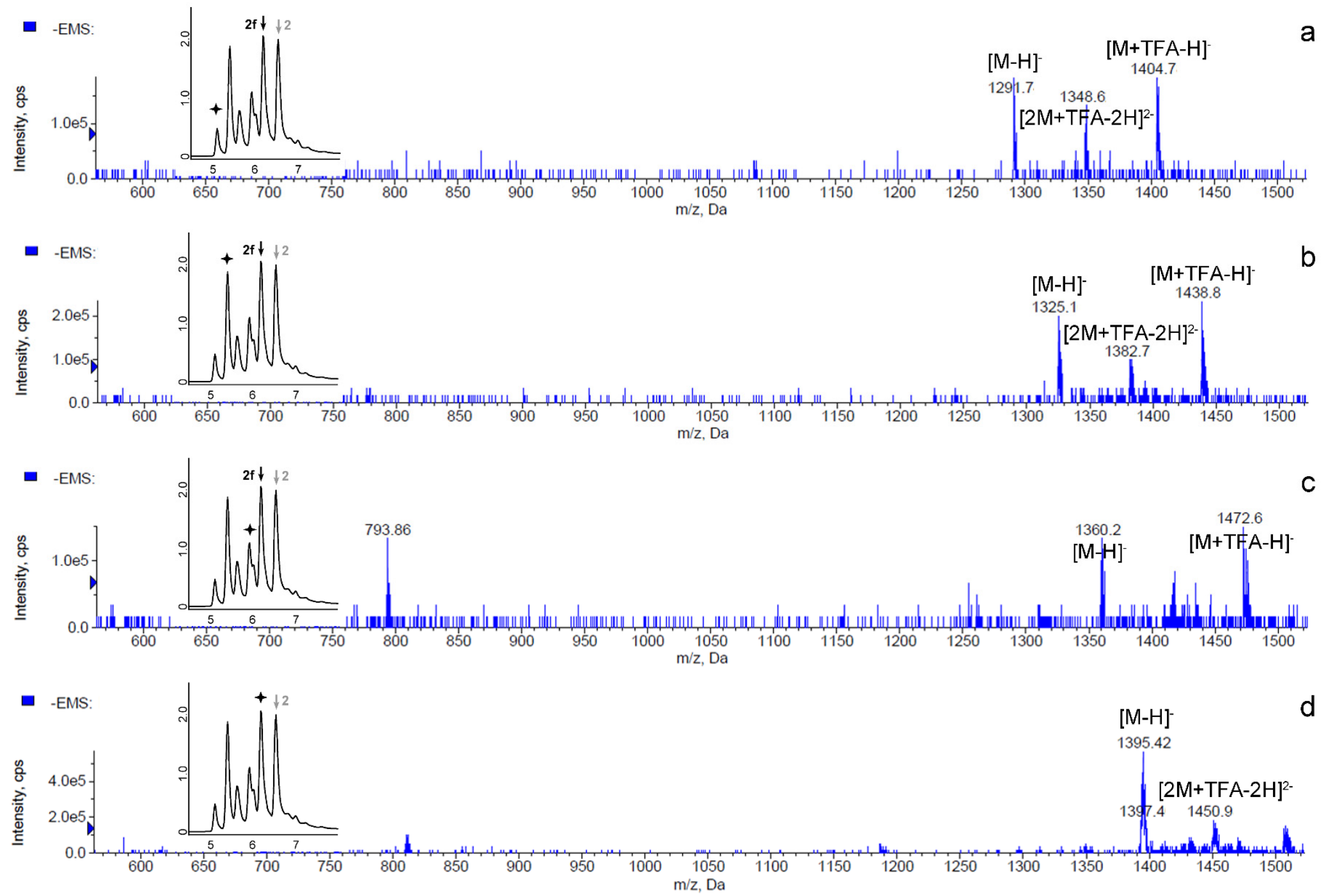

Figure S31. HPLC/ESI-MS of GPA compounds produced by S. coelicolor M1146 pA47934 $\Delta$ staL orf22ris. After affinity chromatography, the partially purified fermentation was fractionated by semi-preparative HPLC and was shown to contain products with zero to three chlorines. The MS of the fractions correspond to the HPLC peaks from Figure 3e indicated by "+" in the inset. The mass spectra of the dechlorinated (a), monochlorinated (b) and di-chlorinated (c) mannosylated precursors of $\mathbf{2 f}(\mathrm{d})$ are shown. 

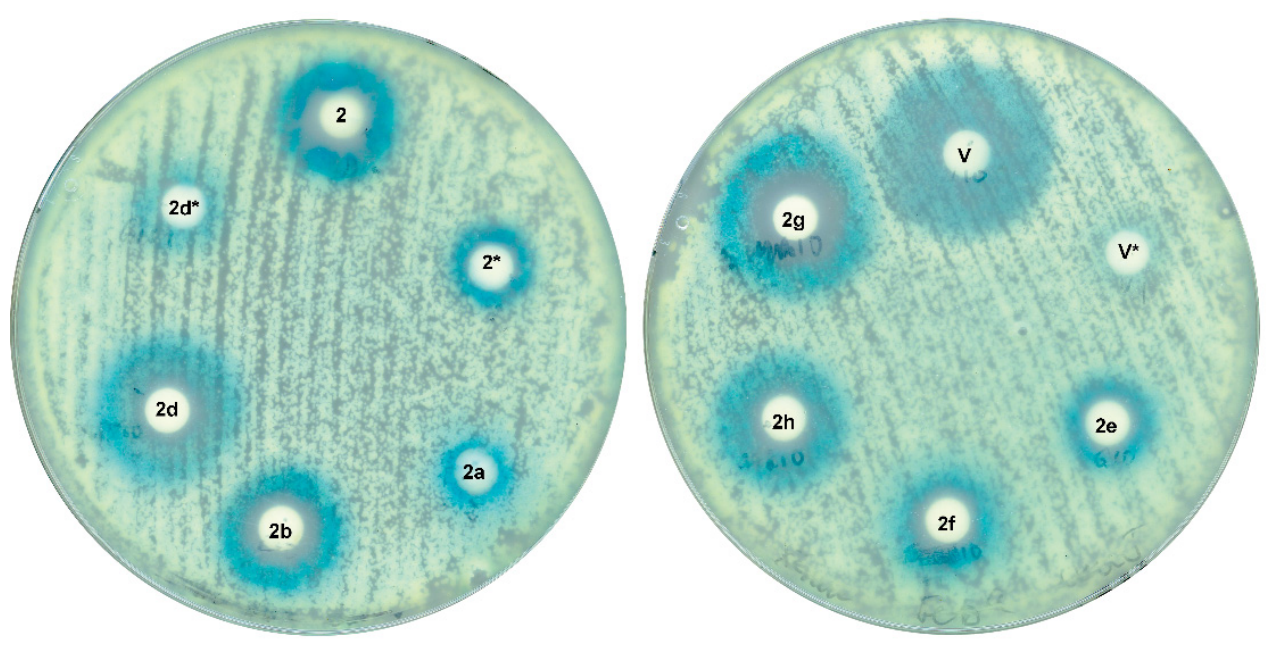

Figure S32. Colorimetric reporter assays with van promoter. Bennett's agar plates containing X-Gluc are swabbed with S. coelicolor M1146 vanJp::gusA.. Filter discs containing either $1 \mu \mathrm{g}$ ( $\left.^{*}\right)$ or $10 \mu \mathrm{g}$ (no. only) of compound (no.) induce van gene expression (blue) as compounds diffuse away from the disc. Some compounds induce expression at high concentrations (close to the disc) while others do not and therefore kill the cells, causing a zone of clearing before inducing growth and expression of the reporter at lower concentrations (farther away from the disc).

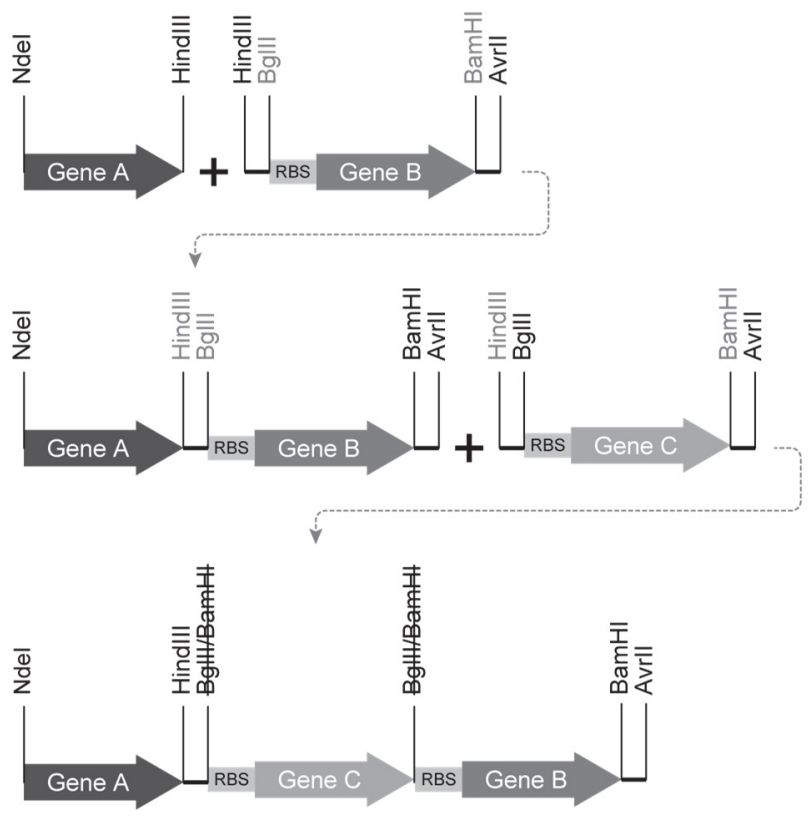

Figure S33. Schematic of restriction sites used to clone tailoring genes into plJ10257 and derivative plasmids. 
Table S1. Theoretical and Observed High Resolution Masses for Compounds 2-1e.

\begin{tabular}{|c|c|c|c|c|c|c|c|}
\hline & $\begin{array}{l}\text { Theor } \\
\text { Mass } \\
{[\mathrm{M}-\mathrm{H}]^{-}}\end{array}$ & $\begin{array}{l}\text { Obs } \\
\text { Mass [M- } \\
\mathrm{H}^{-}\end{array}$ & $\begin{array}{l}\text { Error } \\
(\mathrm{ppm})\end{array}$ & & $\begin{array}{l}\text { Theor } \\
\text { Mass } \\
{[\mathrm{M}-\mathrm{H}]^{-}}\end{array}$ & $\begin{array}{c}\text { Obs } \\
\text { Mass } \\
{[\mathrm{M}-\mathrm{H}]^{-}}\end{array}$ & $\begin{array}{l}\text { Error } \\
\text { (ppm) }\end{array}$ \\
\hline 2 & 1230.1736 & 1230.1738 & 0.16 & 1 & 1310.1304 & & \\
\hline $2 a$ & 1244.1892 & 1244.1895 & 0.24 & $1 a$ & 1324.1460 & 1324.1458 & -0.15 \\
\hline $2 b$ & 1244.1892 & 1244.1896 & 0.32 & $1 b$ & 1324.1460 & 1324.1449 & -0.83 \\
\hline 2c & 1244.1892 & 1244.1886 & -0.48 & 1c & 1324.1460 & 1324.1447 & -0.98 \\
\hline $2 d$ & 1433.2529 & 1433.2540 & 0.77 & 1d & 1513.2098 & 1513.2068 & -1.98 \\
\hline $2 e$ & 1392.2264 & 1392.2269 & 0.36 & $1 e$ & 1472.1832 & 1472.1816 & -1.09 \\
\hline $2 f$ & 1392.2264 & 1392.2263 & -0.07 & & & & \\
\hline $2 g$ & 1310.1304 & 1310.1295 & -0.69 & & & & \\
\hline $2 h$ & 1406.2420 & 1406.2433 & 0.92 & & & & \\
\hline $2 \mathbf{i}$ & $661.5694^{a}$ & $661.5693^{a}$ & -0.15 & & & & \\
\hline $2 \mathrm{j}$ & 1324.1460 & 1324.1453 & -0.53 & & & & \\
\hline
\end{tabular}


Table S2. Selected ${ }^{1} \mathrm{H}$ and ${ }^{13} \mathrm{C}$ assignments of novel derivatives $\mathbf{2 a}$ and $\mathbf{2} \mathbf{d}-\mathbf{2} \mathbf{h}$ in $\mathrm{D}_{2} \mathrm{O}: \mathrm{ACN}-\mathrm{d}_{3}(3: 1, \mathrm{v} / \mathrm{v})$ or in DMSO- $\mathrm{d}_{6}\left({ }^{*}\right)$.

\begin{tabular}{|c|c|c|c|c|c|c|c|c|c|c|c|c|c|c|c|c|c|c|}
\hline & \multicolumn{2}{|c|}{$2 a$} & \multicolumn{2}{|c|}{$2 d$} & \multicolumn{2}{|c|}{$2 d^{*}$} & \multicolumn{2}{|c|}{$2 e$} & \multicolumn{2}{|c|}{$2 \mathrm{e}^{*}$} & \multicolumn{2}{|c|}{$2 f$} & \multicolumn{2}{|c|}{$2 \mathrm{~g}$} & \multicolumn{2}{|c|}{$2 \mathrm{~h}$} & \multicolumn{2}{|c|}{$2 \mathrm{~h}^{*}$} \\
\hline Pos & $\begin{array}{c}{ }^{1}{ }^{1} \mathrm{H} \\
(\mathrm{ppm})\end{array}$ & $\begin{array}{l}{ }^{13} \mathrm{C} \\
(\mathrm{ppm})\end{array}$ & $\begin{array}{c}{ }^{1}{ }^{1} \mathrm{H} \\
(\mathrm{ppm})\end{array}$ & $\begin{array}{l}{ }^{13} \mathrm{C} \\
(\mathrm{ppm})\end{array}$ & $\begin{array}{c}{ }^{1} \mathrm{H} \\
(\mathrm{ppm})\end{array}$ & $\begin{array}{l}{ }^{13} \mathrm{C} \\
(\mathrm{ppm})\end{array}$ & $\begin{array}{c}{ }^{1} \mathrm{H} \\
(\mathrm{ppm})\end{array}$ & $\begin{array}{l}{ }^{13} \mathrm{C} \\
(\mathrm{ppm})\end{array}$ & $\begin{array}{c}\delta{ }^{1} \mathrm{H} \\
(\mathrm{ppm})\end{array}$ & $\begin{array}{l}{ }^{13} \mathrm{C} \\
(\mathrm{ppm})\end{array}$ & $\begin{array}{c}{ }^{1} \mathrm{H} \\
(\mathrm{ppm})\end{array}$ & $\begin{array}{l}\delta^{13} \mathrm{C} \\
(\mathrm{ppm})\end{array}$ & $\begin{array}{c}{ }^{1} \mathrm{H} \\
(\mathrm{ppm})\end{array}$ & $\begin{array}{l}\delta^{13} \mathrm{C} \\
(\mathrm{ppm})\end{array}$ & $\begin{array}{c}{ }^{1}{ }^{1} \mathrm{H} \\
(\mathrm{ppm})\end{array}$ & $\begin{array}{l}\delta^{13} \mathrm{C} \\
(\mathrm{ppm})\end{array}$ & $\begin{array}{c}\delta^{1} \mathrm{H} \\
(\mathrm{ppm})\end{array}$ & $\begin{array}{c}\delta^{13} \mathrm{C} \\
(\mathrm{ppm})\end{array}$ \\
\hline $1 b$ & 7.19 & 121.9 & 7.19 & 121.1 & 6.78 & 120.6 & 7.06 & 121.6 & 6.73 & 120.3 & 7.22 & 121.9 & 6.99 & 120.2 & 7.10 & 120.3 & 6.76 & 120.3 \\
\hline $1 \mathrm{e}$ & 7.39 & 118.9 & 7.38 & 118.2 & 7.01 & 118.9 & 7.23 & 118.7 & 6.99 & 118.7 & 7.40 & 118.9 & 7.25 & 118.8 & 7.32 & 119.6 & 7.01 & 118.6 \\
\hline $1 f$ & 7.57 & 128.8 & 7.55 & 127.8 & 7.16 & 127.2 & 7.38 & 128.6 & 7.15 & 127.2 & 7.57 & 128.8 & 7.42 & 127.1 & 7.52 & 127.3 & 7.18 & 127.1 \\
\hline $2 b$ & 7.64 & 132.0 & 7.63 & 131.2 & 7.22 & 131.6 & 7.50 & 131.7 & 7.22 & 131.5 & 7.66 & 131.8 & 7.57 & 131.6 & 7.73 & 132.1 & 7.21 & 131.4 \\
\hline $2 e$ & 7.53 & 125.0 & 7.57 & 124.2 & 7.22 & 125.3 & 7.35 & 124.5 & 7.16 & 125.2 & 7.52 & 125.0 & 7.47 & 125.2 & 7.65 & 125.0 & 7.18 & 125.1 \\
\hline $2 f$ & 7.89 & 130.6 & 7.91 & 129.9 & 7.82 & 130.8 & 7.72 & 130.7 & 7.71 & 130.8 & 7.91 & 130.8 & 7.75 & 130.0 & 7.96 & 130.5 & 7.81 & 130.8 \\
\hline $3 b$ & 6.81 & 109.9 & 6.85 & 109.1 & 6.35 & 110.5 & 6.72 & 109.7 & 6.35 & 110.5 & 6.87 & 109.9 & 6.66 & 109.9 & 6.86 & 109.7 & 6.34 & 110.4 \\
\hline $3 d$ & 6.88 & 105.6 & 6.84 & 104.6 & 6.37 & 105.5 & 6.72 & 105.2 & 6.38 & 105.6 & 7.00 & 105.8 & 6.80 & 105.6 & 6.89 & 105.6 & 6.38 & 105.5 \\
\hline $3 f$ & 6.52 & 103.7 & 6.52 & 103.1 & 6.39 & 104.2 & 6.44 & 103.8 & 6.33 & 104.4 & 6.63 & 103.9 & 6.40 & 103.4 & 6.54 & 103.5 & 6.36 & 104.3 \\
\hline $4 b$ & 6.02 & 107.2 & 6.00 & 105.5 & 5.49 & 107.9 & 5.90 & 106.7 & 5.53 & 108.9 & 6.04 & 106.9 & 5.92 & 107.9 & 6.10 & 106.7 & 5.52 & 108.3 \\
\hline $4 f$ & 5.57 & 104.1 & 5.68 & 104.1 & 5.10 & 104.9 & 5.51 & 104.4 & 5.08 & 105.3 & 5.55 & 104.2 & 5.48 & 104.2 & 5.80 & 104.9 & 5.29 & 103.1 \\
\hline $5 b$ & 7.32 & 134.3 & 7.34 & 133.6 & 7.11 & 134.8 & 7.22 & 134.1 & 7.08 & 134.6 & 7.36 & 134.2 & 7.09 & 134.0 & 7.20 & 134.3 & 7.10 & 134.7 \\
\hline $5 f$ & 7.32 & 127.4 & 7.24 & 126.7 & 6.80 & 126.3 & 7.13 & 127.3 & 6.80 & 126.3 & 7.38 & 127.1 & 7.19 & 126.5 & 7.23 & 126.9 & 6.80 & 126.3 \\
\hline $6 b$ & 7.87 & 128.0 & 7.79 & 127.3 & 7.74 & 127.5 & 7.71 & 128.0 & 7.73 & 127.5 & 7.88 & 128.0 & 7.97 & 128.0 & 7.94 & 128.3 & 7.73 & 127.6 \\
\hline $6 e$ & 7.06 & 124.1 & & & 7.30 & 124.0 & & & 7.25 & 123.8 & 6.84 & 123.9 & 7.59 & 124.3 & & & 7.28 & 123.8 \\
\hline $6 f$ & 7.75 & 127.8 & 7.59 & 126.9 & 7.46 & 127.8 & 7.47 & 127.4 & 7.44 & 128.1 & 7.75 & 127.8 & 7.79 & 128.2 & 7.72 & 127.7 & 7.45 & 128.0 \\
\hline $7 d$ & 6.89 & 103.5 & 6.87 & 102.7 & 6.42 & 103.1 & 6.76 & 103.5 & 6.38 & 102.8 & 7.25 & 103.3 & 6.75 & 103.3 & 6.87 & 103.4 & 6.42 & 102.9 \\
\hline $7 f$ & 6.58 & 107.2 & 6.73 & 106.7 & 6.28 & 106.5 & 6.61 & 107.4 & 6.32 & 105.6 & 6.90 & 109.0 & 6.74 & 107.9 & 6.81 & 108.1 & 6.26 & 106.4 \\
\hline Z2 & 3.40 & 36.4 & 3.41 & 35.7 & 2.88 & 36.6 & 3.27 & 36.5 & 2.89 & 36.4 & 3.42 & 36.7 & 3.31 & 36.3 & 3.46 & 36.6 & 2.91 & 36.3 \\
\hline Z2' & 3.68 & 36.4 & 3.69 & 35.7 & 3.37 & 36.6 & 3.54 & 36.5 & 3.35 & 36.4 & 3.72 & 36.7 & 3.58 & 36.3 & 3.75 & 36.6 & 3.35 & 36.3 \\
\hline Z6 & 5.72 & 71.7 & 5.72 & 70.7 & 5.11 & 71.9 & 5.62 & 71.4 & 5.12 & 71.7 & 5.77 & 71.6 & 6.09 & 77.4 & 5.82 & 71.7 & 5.10 & 71.8 \\
\hline
\end{tabular}

Key differences between $\mathbf{2} \mathbf{g}$ and other compounds are bolded. 
Table S3. Expected and observed masses from strains with two gene integrations.

\begin{tabular}{|c|c|c|c|c|c|}
\hline & & M1146 & 447934 & M1146 ph & $7934 \Delta s t a L$ \\
\hline $\begin{array}{l}\text { Genes in } \\
\phi B T 1 \text { attB }\end{array}$ & Predicted Modification(s) & $\begin{array}{l}\text { Expected } \\
\text { Mass }\end{array}$ & $\begin{array}{l}\text { Observed } \\
\text { Mass }\end{array}$ & $\begin{array}{l}\text { Expected } \\
\text { Mass [M- }\end{array}$ & $\begin{array}{l}\text { Observed } \\
\text { Mass }\end{array}$ \\
\hline & & {$[\mathrm{M}-\mathrm{H}]^{-}$} & {$[\mathrm{M}-\mathrm{H}]^{-}$} & $\mathrm{H}]^{-}$ & {$[\mathrm{M}-\mathrm{H}]^{-}$} \\
\hline orf22 ris & Mannose (aa 7) & 1472 & - & 1392 & 1392 \\
\hline auk20 & $\mathrm{SO}_{3}($ aа 3) & 1390 & - & 1310 & 1310 \\
\hline & Both & 1552 & - & 1472 & - \\
\hline$m t f A_{p e k}$ & $\mathrm{CH}_{3}(\mathrm{~N}$ term $)$ & 1324 & 1324 & 1244 & 1244 \\
\hline auk20 & $\mathrm{SO}_{3}(\mathrm{aa} 3)$ & 1390 & - & 1310 & - \\
\hline & Both & 1404 & - & 1324 & 1324 \\
\hline $\operatorname{teg} 13$ & $\mathrm{SO}_{3}(\mathrm{aa} 6)$ & 1390 & - & 1310 & $1310^{a}$ \\
\hline auk20 & $\mathrm{SO}_{3}($ aa 3) & 1390 & - & 1310 & $1310^{a}$ \\
\hline & Both & 1470 & - & 1390 & - \\
\hline orf23ris & $\mathrm{CH}_{3}(\mathrm{aa} 3)$ & 1324 & 1324 & 1244 & - \\
\hline $\operatorname{teg} 14$ & $\mathrm{SO}_{3}$ (aa 4) & 1390 & - & 1310 & 1310 \\
\hline & Both & 1404 & - & 1324 & 1324 \\
\hline orf22ris & Mannose (aa 7) & 1472 & $1392^{b}$ & 1392 & 1392 \\
\hline $\operatorname{teg} 14$ & $\mathrm{SO}_{3}(\mathrm{aa} 4)$ & 1390 & - & 1310 & - \\
\hline & Both & 1552 & - & 1472 & - \\
\hline $\operatorname{teg} 13$ & $\mathrm{SO}_{3}(\mathrm{aa} 6)$ & 1390 & - & 1310 & $1310^{a}$ \\
\hline $\operatorname{teg} 14$ & $\mathrm{SO}_{3}$ (aa 4) & 1390 & - & 1310 & $1310^{a}$ \\
\hline & Both & 1470 & - & 1390 & - \\
\hline gtfE $E_{\mathrm{van}}$, & Glucose (aa4) & 1472 & $1392^{b}$ & 1392 & 1392 \\
\hline orf14pek & 2-O-methyl glucose (aa 4) & 1486 & - & 1406 & 1406 \\
\hline $\begin{array}{l}\text { '-' indicates } \\
\text { mass of the } \\
2 \text { from M11 } \\
\text { 'a' indicates } \\
\text { 'b”' mass me }\end{array}$ & $\begin{array}{l}\text { mass consistent with the pre } \\
\text { ffold mass(es) were observe } \\
\text { A47934 } \Delta \text { staL } \\
\text { there are several locations } \\
\text { es that of the } 2 \text { derivative }\end{array}$ & $\begin{array}{l}\text { mass of } 1 \\
\text { ere sulpha }\end{array}$ & $\begin{array}{l}\text { Ion was ob } \\
\text { d } 2 \text { from } M \\
\text { could hav }\end{array}$ & $\begin{array}{l}\text { ved, only } \\
46 \text { pA4793 } \\
\text { ccurred }\end{array}$ & $\begin{array}{l}\text { scaffold } \\
\text { and mass of }\end{array}$ \\
\hline
\end{tabular}


Table S4. Oligonucleotides used in this study

\begin{tabular}{|c|c|c|}
\hline Primer & Sequence (5' to $\left.3^{\prime}\right)$ & Use \\
\hline \multicolumn{3}{|c|}{ Cloning of tailoring genes } \\
\hline $\begin{array}{l}\text { 4229Stf } \\
\text { Ndel F }\end{array}$ & AAACATATGAACCAAATCCGATGGATC & \\
\hline $\begin{array}{l}\text { 4229Stf } \\
\text { HindIII R }\end{array}$ & TTTAAGCTTCAGTCGGCGTACCCGTAC & \\
\hline $\begin{array}{l}\text { TEG13 } \\
\text { Ndel F2 }\end{array}$ & TTTCATATGAACGGCATCCGGTGG & \\
\hline $\begin{array}{l}\text { TEG13 } \\
\text { HindIII R2 }\end{array}$ & TTTAAGCTTCAGCCCGCGTAGCCGTAC & \\
\hline $\begin{array}{l}\text { MtfA } \\
\text { WAC4229 } \\
\text { Ndel F }\end{array}$ & TTTCATATGAGTGATCAGCTGGAGCACG & \\
\hline $\begin{array}{l}\text { MtfA } \\
\text { WAC4229 } \\
\text { HindIII R }\end{array}$ & TTTAAGCTTCATGCGGGACCGGTCTTC & \\
\hline $\begin{array}{l}\text { C-Mtf Ndel } \\
\text { F2 }\end{array}$ & TTTCATATGTCGTTCTCAACGTCTGCG & \\
\hline $\begin{array}{l}\text { C-Mtf } \\
\text { HindIII R }\end{array}$ & TTTAAGCTTCAGGGCTTGGTGCCGGT & \\
\hline $\begin{array}{l}\text { MGtf ris } \\
\text { Ndel F }\end{array}$ & TTTCATATGTCCGCAACACTCACCC & \\
\hline $\begin{array}{l}\text { MGtf ris } \\
\text { HindlII R }\end{array}$ & TTTAAGCTTCAGAAGGAGCCGGACGC & \\
\hline $\begin{array}{l}\text { OMtf ris } \\
\text { Ndel F }\end{array}$ & TTTCATATGTCCGATCTGGCTGCAGCACCGC & \\
\hline $\begin{array}{l}\text { OMtf ris } \\
\text { HindlII } R\end{array}$ & TTTAAGCTTCAGCGCCGGACCGCGGCG & \\
\hline $\begin{array}{l}\text { gtfE Ndel F } \\
\text { gtfE Hindlll } \\
\text { R }\end{array}$ & $\begin{array}{l}\text { AAAACATATGCGTGTGCTGTTGGCGAC } \\
\text { TTTAAGCTTTCACGCGGGAACGGCGG }\end{array}$ & \\
\hline $\begin{array}{l}\text { teg14-F } \\
\text { HindIII }\end{array}$ & AAAAAGCTTAGATCTAGGAGGATATCA & \\
\hline $\begin{array}{l}\text { teg14-R } \\
\text { Avrll }\end{array}$ & AAACCTAGGATCCTCAGCCCGCGTAGC & \\
\hline $\begin{array}{l}\text { orf14 }{ }_{\text {pek }}-\mathrm{F} \\
\text { HindlII }\end{array}$ & AAAAAGCTTAGATCTAGGAGGATGCAC & \\
\hline $\begin{array}{l}\text { orf14 pek-R } \\
\text { Avrll }\end{array}$ & AAACCTAGGTCACTTCCTTGCGACGAC & \\
\hline $\begin{array}{l}\text { auk20 F } \\
\text { HindIII }\end{array}$ & AAAAAGCTTAGATCTAGGAGGCAATCAT & \\
\hline $\begin{array}{l}\text { auk20 R } \\
\text { Avrll }\end{array}$ & AAACCTAGGATCCTCACTCGTCGTAGCC & \\
\hline $\begin{array}{l}\text { pLK2 } \\
\text { screen F }\end{array}$ & GCTGTTGTGGGCACAATC' & $\begin{array}{l}\text { Sequencing of plJ10257 } \\
\text { derivatives }\end{array}$ \\
\hline $\begin{array}{l}\text { BT1 } \\
\text { screenR }\end{array}$ & AGCAAGGCAAGACCGATC & $\begin{array}{l}\text { Sequencing of plJ10257 } \\
\text { derivatives }\end{array}$ \\
\hline Construction & of transcriptional fusions & \\
\hline $\begin{array}{l}\text { vanHp } \\
\text { Xbal F }\end{array}$ & & Reporter construction \\
\hline $\begin{array}{l}\text { vanHp } \\
\text { Kpnl R } \\
\text { PAC vector }\end{array}$ & & Reporter construction \\
\hline
\end{tabular}




\begin{tabular}{|c|c|c|}
\hline dpgC F & GGGCDSGAGATCGAYCAGGG & $\begin{array}{l}\text { Diagnostic for cluster } \\
\text { integration }\end{array}$ \\
\hline dpgC R & AGGTTCAGCATSCGCCGGTTG & $\begin{array}{l}\text { Diagnostic for cluster } \\
\text { integration }\end{array}$ \\
\hline staN $2 \mathrm{~F}$ & ACGAACTGGACTTCGCCCTTCTTC & $\begin{array}{l}\text { Diagnostic for cluster } \\
\text { integration }\end{array}$ \\
\hline staN 2R & GTAGAGGAGGACGCCCAGGAACAG & $\begin{array}{l}\text { Diagnostic for cluster } \\
\text { integration }\end{array}$ \\
\hline $\operatorname{vanA} \mathrm{F}$ & AACGGATCTCGTCGTGGG & vanAX knock in \\
\hline $\operatorname{van} X \mathrm{R}$ & CTACATGATGGGGAAATCGAAG & vanAX knock in \\
\hline $\begin{array}{l}\text { T7 } \\
\text { promoter } \mathrm{F}\end{array}$ & TAATACGACTCACTATAGGG & $\begin{array}{l}\text { Diagnostic for cluster } \\
\text { integration }\end{array}$ \\
\hline staL KO for & $\begin{array}{l}\text { GCCCGCCGCGTCGAAGGAACGAGAGGACGCCCG } \\
\text { ATGAACGTGTAGGCTGGAGCTGCTTC }\end{array}$ & Deletion of staL \\
\hline $\begin{array}{l}\text { staL KO } \\
\text { rev }\end{array}$ & $\begin{array}{l}\text { AACATCGAGCGGTGTCGGACTGTTCAAGCGGGG } \\
\text { AATTCACATATGAATATCCTCCTTAG }\end{array}$ & Deletion of staL \\
\hline pKD3 P1 & $\begin{array}{l}\text { CTTCGATTTCCCCATCATGTAGGTGTAGGCTGGA } \\
\text { GCTGCTTC }\end{array}$ & vanAX knock in \\
\hline pKD3 P2 & $\begin{array}{l}\text { TTTGCGGCCGCTAATACGACTCACTATAGGGAGA } \\
\text { GGATCCCATATGAATATCCTCCTTA }\end{array}$ & vanAX knock in \\
\hline $\begin{array}{l}\text { pKD3 } \\
\text { internal }\end{array}$ & GAGCATTCATCAGGCGGGC & \\
\hline $\begin{array}{l}\text { staK KOus } \\
\text { for }\end{array}$ & AGTCCCTGTGGCGACGGTTC & Diagnostic for staL deletion \\
\hline $\begin{array}{l}\text { staL KOds } \\
\text { rev }\end{array}$ & GTCGCGTCAGGGCAACATC & Diagnostic for staL deletion \\
\hline
\end{tabular}




\section{Supplemental Methods}

\section{Completion of pA47934 and deletion of staL}

The lamba red system (26) was used to complete the biosynthetic cluster and to subsequently delete the $s t a L$ gene. Three amplicons were generated for addition of vanAX to the PAC vector. PCR product one was amplified using the primers vanA $F$

and vanX R and $S$. toyocaensis genomic DNA as a template. A second PCR product amplifying cat was generated using the primers pKD3 P1 and pKD3 P2 and the template plasmid pKD3 (26). A third composite PCR product was generated using the primers vanAF and pKD3 with the first and second PCR products as a template. The composite PCR product was electroporated into BW25113 carrying pA47934partial and pKD46. The cat resistance cassette was removed using pCP20 as described previously (26) to create pA47934. The vector pA47934 was targeted for deletion of staL and removal of cat as described above except the targeting PCR product was generated using the primers staL KO for and rev (Table S4) and pKD3 as a template.

\section{Cloning of tailoring genes}

Primers for cloning the first gene into plJ10257 were designed to append Nde I and Hind III restriction sites to the 5' and 3' end, respectively, of PCR products. PCR products and plJ10257 were digested with Nde I and Hind III and ligated together with T4 DNA ligase. Error-free constructs were transformed into ET12567 /pUZ8002 for conjugation into Streptomyces.

When a second tailoring gene was cloned into an integrating vector containing one tailoring gene, oligonucleotides for the second cassette were designed to append Hind III and BgI II sites to the 5' end of the amplicon and BamH I and Avr II to the 3' end (unless the coding sequence contained one of these restrictions sites and the respective site was removed from the primer). These gene cassettes could also be used as a third gene if plasmids with two gene inserts are digested with Hind III and $\mathrm{Bgl}$ $\mathrm{II}$ and the incoming cassette with Hind III and BamH I. Alternatively, plasmids with two

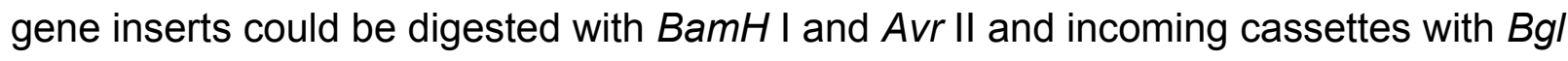
II and Avr II (Fig S33). Ribosome binding sites were designed into the forward primer. No transcription terminators were inserted so transcription was expected to read 
through from the ermEp* promoter present in front of the first tailoring gene. PCR products and plasmid were digested with Hind III and Avr II and ligated together with T4 DNA ligase. Error-free constructs were transformed into ET12567/pUZ8002 for conjugation into Streptomyces.

\section{RP-HPLC Separation}

All analytical and semi-preparative RP-HPLC was carried out on a Waters 2998 photodiode array detector and e2695 separation module. Most analytical separation was performed using a flow rate of $1 \mathrm{ml} / \mathrm{min}$ starting at $10 \%$ acetonitrile with $0.05 \%$ trifluoroacetic acid (solvent $B$ ) in water with $0.05 \%$ trifluoroacetic acid (solvent $A$ ) for 1 minute, followed by a $10-45 \%$ linear gradient of $B$ for seven minutes. For fermentations of $\mathbf{2 b}$ and $\mathbf{2 c}$, separation began at $5 \%$ solvent $B$ for $30 \mathrm{~s}$, followed by a linear gradient of $5-18 \%$ of solvent $B$ for $1 \mathrm{~min}$, isocratic separation at $18 \%$ B for 13.5 minutes, followed by a linear gradient of $18-28 \%$ B over 7.8 minutes. 